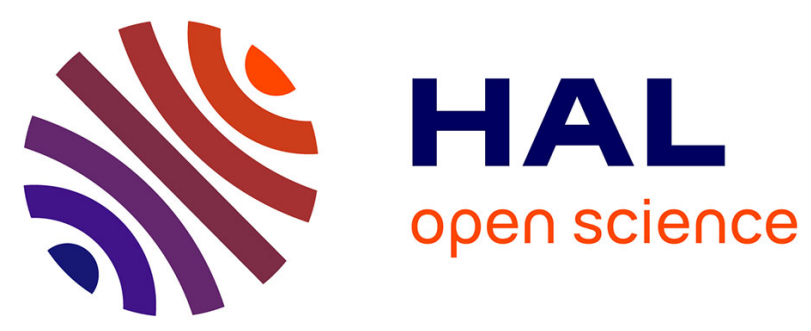

\title{
Instrumented incremental sheet testing for material behavior extraction under very large strain : information richness of continuous force measurement
}

Gemala Hapsari, Fabrice Richard, Ramzi Ben Hmida, Pierrick Malecot, Sébastien Thibaud

\section{To cite this version:}

Gemala Hapsari, Fabrice Richard, Ramzi Ben Hmida, Pierrick Malecot, Sébastien Thibaud. Instrumented incremental sheet testing for material behavior extraction under very large strain: information richness of continuous force measurement. Materials \& Design, 2018, 140, pp.317 - 331. hal-03427025

\section{HAL Id: hal-03427025 \\ https://hal.science/hal-03427025}

Submitted on 12 Nov 2021

HAL is a multi-disciplinary open access archive for the deposit and dissemination of scientific research documents, whether they are published or not. The documents may come from teaching and research institutions in France or abroad, or from public or private research centers.
L'archive ouverte pluridisciplinaire $\mathbf{H A L}$, est destinée au dépôt et à la diffusion de documents scientifiques de niveau recherche, publiés ou non, émanant des établissements d'enseignement et de recherche français ou étrangers, des laboratoires publics ou privés. 


\section{Accepted Manuscript}

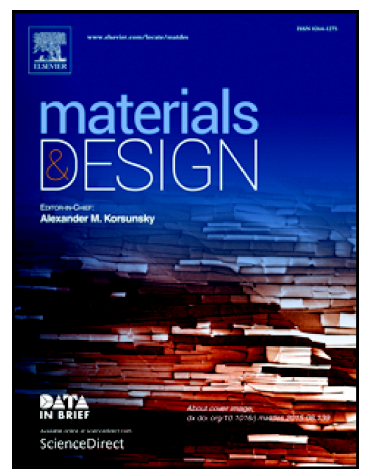

G. Hapsari, F. Richard, R. Ben Hmida, P. Malécot, S. Thibaud

PII:

S0264-1275(17)31107-3

DOI: doi:10.1016/j.matdes.2017.12.002

Reference:

JMADE 3553

To appear in:

Materials \& Design

Received date:

4 October 2017

Revised date:

15 November 2017

Accepted date:

1 December 2017

Please cite this article as: G. Hapsari, F. Richard, R. Ben Hmida, P. Malécot, S. Thibaud , Instrumented Incremental Sheet Testing for material behavior extraction under very large strain: Information richness of continuous force measurement. The address for the corresponding author was captured as affiliation for all authors. Please check if appropriate. Jmade(2017), doi:10.1016/j.matdes.2017.12.002

This is a PDF file of an unedited manuscript that has been accepted for publication. As a service to our customers we are providing this early version of the manuscript. The manuscript will undergo copyediting, typesetting, and review of the resulting proof before it is published in its final form. Please note that during the production process errors may be discovered which could affect the content, and all legal disclaimers that apply to the journal pertain. 


\title{
Instrumented Incremental Sheet Testing for material behavior extraction under very large strain: information richness of continuous force measurement
}

\author{
G. Hapsari, F. Richard, R. Ben Hmida, P. Malécot, S. Thibaud
}

Univ. Bourgogne Franche-Comté - FEMTO-ST Institute - CNRS/UFC/ENSMM/UTBM

Corresponding author:

Sébastien Thibaud

sebastien.thibaud@ens2m.fr

Tel: +33-(0)3-81-66-66-11

Department of Applied Mechanics

24 rue de l'Epitaphe

25000 Besançon-FR

\section{Highlights}

- Estimation of material parameters from micro incremental sheet forming test using forming force measurements by finite element model updating method.

- Identification of coupled ductile damage behavior in very large strain of thin copper foils during incremental deformation test.

- Quantification of forming force information richness with an identifiability index to ensure no correlation between the material parameters and to enable an optimization of the characterization test. 


\section{Abstract}

Incremental forming is a rapid prototyping process which uses a forming tool to form a sheet metal according to a predetermined trajectory. In this paper, a micro incremental deformation test (Micro InDef test) derived from the principle of single point incremental sheet forming is developed and proposed. A complex mechanical loading is applied and has a strong potential for the identification of inelastic behavior using inverse method.

In a first part, this paper addresses the parameters identification and validation procedures of the ductile damage behavior of ultra-thin sheet metal under very large strain during this instrumented Micro InDef test. An inverse finite element method based on the comparison between numerical and experimental axial forming forces of the incremental deformation test is employed to extract a coupled ductile damaged plastic model.

In the last part, the objective is to prove the reliability of ductile damage parameters identification using forming force. The richness of data contained in forming force is quantified and compared to the one from tensile test. Firstly the verification of the estimated parameter' reliability is done via a simple analysis based on the forming force sensitivity to material parameters and secondly by calculating elastoplastic and elastoplastic with ductile damage.

Keywords: Damage; Micro incremental deformation test; Finite Element Method; Inverse method; Identifiability 


\section{INTRODUCTION}

The developed Micro Incremental Deformation (Micro InDef) test consists of locally deformed a clamped blank using a hemispherical tool. The advantages of this test are, the magnitude of deformation achieved is considerably large and it can be performed on a CNC milling machine, where the deformation path can be varied easily. These characteristics are also known for incremental sheet forming (ISF), considering the Micro InDef test reproduces the same procedure but with different goal, moreover for the Micro InDef test a dynamometer is used to measure the forming force. While ISF aims to form the sheet without the need of dedicated dies or specific tooling, Micro InDef test's objective is to make useful of the large and complex deformation to obtain the material's parameters.

Numerical simulations of sheet forming are widely used in the research and development areas. These simulations have become an indispensable tool in product design to improve both performance and quality, as well as reducing costs. The mastery of numerical modeling is a preliminary step in processes optimizations and in understanding complex phenomena. However, the quality of the numerical simulations depends on the accuracy of the input data, such as the boundary conditions, loading conditions, the constitutive law, and the material parameters.

Regarding thin sheet metal, the identification of the constitutive law is often performed by using classical characterization tests, i.e., tensile, bending, and shear tests. The strain level reached by these tests is limited and does not represent the complex and large deformations that occur during metal forming operations. The characterization of the material behavior of these tests is thus insufficient for accurate forming processes prediction.

Previous studies have shown that the accumulated plastic strain threshold and the damage evolution can be identified using repeated tensile loading [1]. It is satisfactory for the applications at moderate plastic strain levels $(\mathrm{r}<30 \%)$ on metal sheets having thicknesses greater than $1 \mathrm{~mm}$. Abbassi et al. [2] have calibrated the GursonTvergaard-Needleman (GTN) model by using the results of the tensile test. The validation is carried out by comparing the experimental and numerical results of bulge test and Erichsen test.

In this study, the detection of Young's modulus variation during tensile tests using current technology is impossible due to the thinness of the specimen and strain localization at about $r=30 \%$. For this test, the softening part of load-displacement curve is due to damage growth and to necking. Consequently, the information 
contained in load-displacement curve is too poor to identify damage parameters and this will be confirmed later by the identifiability analysis.

Shim and Park [3] have shown that an incremental deformation depends on the forming strategy and can reach an accumulated plastic strain two to three times higher than traditional stamping processes. Park et al. [4] have assessed the formability of an aluminum sheet under various forming conditions. They have shown that the incremental deformation of sheet with highly non-monotonic serrated strain paths, can undergo higher plastic deformation than traditional sheet metal forming.

This high formability can be explained by the fact that the deformation concentration region moves along the position of the contact tool/sheet. This phenomenon prevents the development of necking and delays the failure of the blank. This advantage allows the extraction of a lot of information about the material in very large strain. Therefore, we will use Micro InDef test to calibrate the ductile damage model by using the finite element updating method. The coupled damage-plasticity constitutive law used in this study is Lemaitre's type, which will be described in the overview.

The deformation process and forces evolution during the above mentioned procedure are already well known. Jeswiet et al. [5] and Emmens and Van den Boogard [6] mentioned the localized deformation where the area of plastic strain is moving along the incremental path of the tool on the material. Jackson and Allwood [7] found experimentally that deformation occurs is a combination of bending, stretching and shear which increases during the successive laps. With the greatest strain component is shear in the tool direction, while perpendicular to the tool direction - stretching and shear have the same magnitude. Vollertsen et al. [8] have given a review on size effects and their potential use via the description of their influence on the formability and on the forming processes. Ben Hmida et al. [9] have investigated these phenomena by studying the influence of the initial grain size on the forming forces. They found that the axial force decreases with increasing grain size, which is in agreement with the Hall-Petch effect [10-11].

Furthermore, several studies have shown that the force predictions made from finite element (FE) simulations of incremental sheet deformation are sensitive to the material parameters. By FE simulations Henrard et al. [12] have observed that the force prediction is highly sensitive to the constitutive law and the material parameters. Duflou et al. [13] found that the axial forming force is the dominant force and is close to the total force. 
For all these reasons we decided to use the axial force as data for inverse problem approach. This approach proposes to determine constitutive parameters from the measured response data, namely, using the finite element model updating (FEMU) method. Early attempts to use this approach have been presented by Kavanagh and Clough [14]. The objective is to minimize the gap between a result response of a finite element simulation and the measured quantity. Several studies have used local measurements response, such as the displacement fields, e.g., Pottier et al. [15] have applied the FEMU method, using digital image correlation data, to identify the parameter set of an anisotropic elastic-plastic model. The full-field data are experimentally obtained from three geometries exhibiting increasing strain field heterogeneities. Several authors have applied this method using global measurements response, such as reaction force and torque. In this context, Gelin and Ghouati [16] have used this technique to determine viscoplastic material parameters of an aluminum alloy from a plane strain compression test. Later, they applied this method to identify the elastic plastic constitutive law parameters using tensile tests in a first step and a deep-drawing test in a second one [17]. Moreover, Yoshida et al. [18] have successfully identified elastic plastic parameters for sheet metal using the inverse method from cyclic bending tests.

In the instrumented Micro InDef test, the global forming measurement force is used to characterize the material behavior of thin sheets under complex loading conditions. In this paper, the identification of a ductile damage model is carried out. It should be noted that the main goal of Micro InDef test is to identify a mechanical behavior (hereto a Lemaitre type behavior), and not to simulate incremental forming process. A calibration procedure is proposed to estimate the associated material parameters using the FEMU method. Then the Micro InDef test of different tool path is realized to validate the inelastic behavior. Finally, a practical identifiability analysis via an index based on the forming force sensitivity is performed to quantify the information richness of forming forces measurement.

\section{MATERIAL \& METHODS}

In this section, the material and the considered mechanical behavior law are introduced. The micro incremental deformation test is then presented and applied to calibrate the constitutive parameters of the considered behavior law. Different tests are also performed to demonstrate the ability of identified behavior law to simulate different deformation paths. Finally, the richness of data contained in forming force is quantified to validate the parametric identification procedure. 


\section{II.1. Material and considered behavior law}

The selected material for this study is a single-phase copper foil with an initial thickness of $210 \mu \mathrm{m}$. The chemical composition of the copper alloy is as follows: $\mathrm{Cu}(99.9 \%)$ and $\mathrm{Fe}(0.1 \%)$. The material is annealed at $400^{\circ} \mathrm{C}$ for $30 \mathrm{~min}$ to eliminate the effects of rolling texture and to make the structure homogeneous. The average grain size after annealing is equal to $30 \mu \mathrm{m}$.

The elastic parameters obtained from ultrasonic characterization are $100 \mathrm{GPa}$ for the Young Modulus and 0.31 for the Poisson's ratio. These values are in good agreement with literature data [19].

Uniaxial tensile tests were conducted on flat specimens having a rectangular cross section $A_{0}=w_{0} h_{0}$ where $w_{0}=5 \mathrm{~mm}$ and $h_{0}=0.21 \mathrm{~mm}$ are the initial specimen width and thickness, respectively. True stress $\sigma$ and true strain $\varepsilon$ are calculated from the following relation

$\sigma=\frac{F_{t}}{A_{0}}(1+\varepsilon)$

$\varepsilon=\ln \left(1+\frac{\Delta l}{l_{0}}\right)$

where $F_{t}, \Delta l$ and $l_{0}$ are respectively the tensile force measured by the load cell, the length variation measured by the laser extensometer and the initial length $\left(l_{0}=25 \mathrm{~mm}\right)$.

Specimens were cut from a strip with a width of $34 \mathrm{~mm}$ by wire electrical discharge machining process, in three directions: $0^{\circ}, 45^{\circ}$ and $90^{\circ}$ with respect to the rolling direction. The specimen was elongated up to fracture, and the true stress-strain curve was obtained for the three orientations $\left(0^{\circ}, 45^{\circ}\right.$ and $\left.90^{\circ}\right)$. The stress-strain curves are presented in Fig. 1.

The stress-strain curves show small deviations, as presented in Fig. 1a. The three Lankford coefficients (r0, r45 and r90) are measured at $20 \%$ of strain. The calculated normal anisotropy $R_{N}$ and the planar anisotropy are $R_{N}=0.955$ and $\Delta R=-0.12$, respectively. These results demonstrate that the material can be considered isotropic.

Three tensile tests with different strain rates $\dot{\varepsilon}\left(10^{-1}-10^{-3} \mathrm{~s}^{-1}\right)$ were carried out to study the influence of strain rate on the sheet metal plastic behavior. It is found that the strain rate does not have a significant impact on the material mechanical behavior, as shown in Fig. 1b. Only a slight increase in the stresses with the strain rate is observed (3\%). The sensitivity to the strain rate is therefore not considered. 


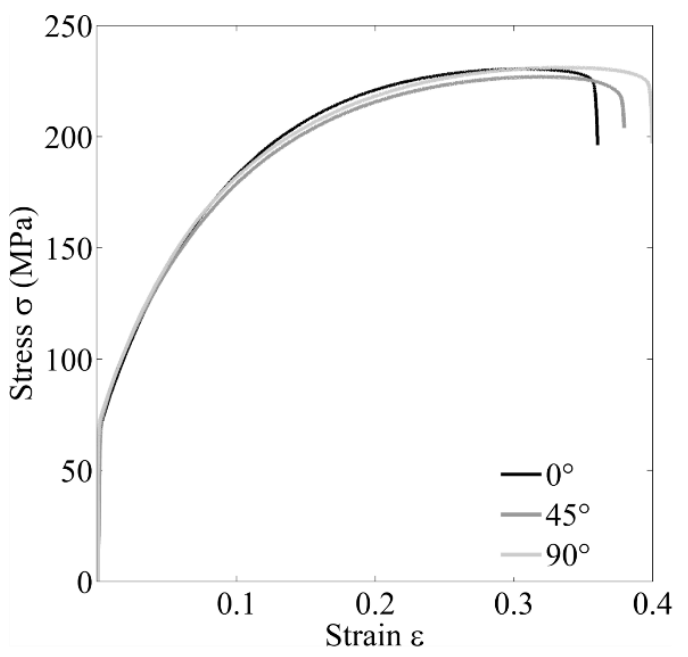

(a)

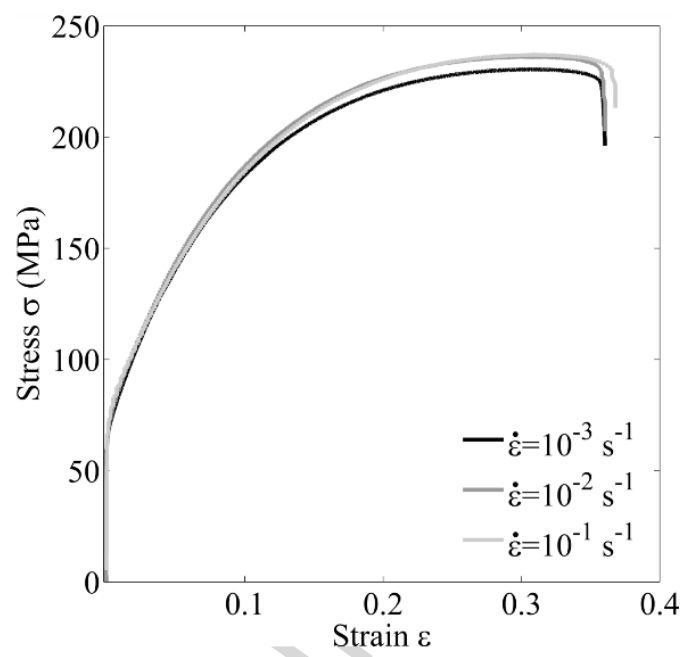

(b)

Fig. 1: True stress-true strain curves: (a) cutting direction effect $\left(\dot{\varepsilon}=10^{-3} \mathrm{~s}^{-1}\right)$,

(b) strain rate effect (direction: $0^{\circ}$ ).

In this section, the damage-plasticity isotropic model is presented, in the isothermal case, to provide an accurate prediction of the mechanical response of the material. The continuum damage mechanics concepts developed by Lemaitre and Desmorat [20] in the context of thermodynamics with internal variables are considered [1]. In this approach, damage is coupled with the plasticity model by using the effective stress concept.

Starting from the early propositions of Kachanov [21] and Rabotnov [22], a scalar damage variable $D$ that characterizes the degree of material degradation is introduced. By assuming homogeneous distribution of microvoids, the effective stress tensor can represented as

$\tilde{\boldsymbol{\sigma}}=\frac{\boldsymbol{\sigma}}{1-D}$

Where $\boldsymbol{\sigma}$ is the Cauchy stress tensor and $\tilde{\boldsymbol{\sigma}}$ is the effective stress tensor. The damage variable $D$ may be interpreted as an indirect measurement of microvoids and microcracks density for which values between 0 (initial undamaged state) and $D_{c}$ the critical damage, can be assumed, defining the local failure $\left(0 \leq D \leq D_{c} \leq\right.$ 1).

By applying the elastic strain equivalence assumption [1], the strain behavior of the damage model is represented by the constitutive equation of the virgin material, where stress is simply replaced by effective stress.

$\boldsymbol{\varepsilon}^{e}=\mathbf{C}^{-1}: \tilde{\boldsymbol{\sigma}}=\widetilde{\mathbf{C}}^{-1}: \boldsymbol{\sigma} \Rightarrow \widetilde{\mathbf{C}}=(1-D) \mathbf{C}$

Where $\boldsymbol{\varepsilon}^{e}$ is the elastic strain and $\mathbf{C}$ and $\widetilde{\mathbf{C}}$ are the elastic constitutive tensors for the virgin and the damaged material, respectively, with 
$\mathbf{C}=\frac{E}{(1+v)}\left[\mathbf{I}+\frac{v}{(1-2 v)} \mathbf{l} \otimes \mathbf{I}\right]$

Where $\mathbf{I}$ and $\mathbf{I}$ are the fourth and second order unit tensors respectively. $v$ is the Poisson ratio and $E$ is the virgin (undamaged) Young's modulus.

By using the strain partition hypothesis, the total strain $\varepsilon$ can be divided into elastic $\boldsymbol{\varepsilon}^{\boldsymbol{e}}$ and plastic $\boldsymbol{\varepsilon}^{p}$ parts:

$\varepsilon=\varepsilon^{e}+\varepsilon^{p}$

The non-associated plasticity framework assumes that mechanical behavior is obtained when three potentials are defined to determine the flow direction: a specific free energy $\psi$, a yield function $f$ and dissipation potential $F$. By applying the assumption that elasticity and plasticity behaviors are uncoupled, the following expression is proposed for the free energy

$\rho \psi\left(\boldsymbol{\varepsilon}^{e}, r, D\right)=\frac{1}{2}(1-D) \boldsymbol{\varepsilon}^{e}: \mathbf{C}: \boldsymbol{\varepsilon}^{e}+Q r+\frac{Q}{b}[\exp (-b r)-1]$

Where $\rho$ is the density and $Q r+Q / b[\exp (-b r)-1]$ is the plastic stored volume density energy and $r$ is the accumulated damaged plastic strain. $Q$ and $b$ are material parameters that represent the asymptotic value and the exponent of the isotropic hardening law, respectively [23]. The state laws can be then written as

$\boldsymbol{\sigma}=\rho \frac{\partial \psi}{\partial \boldsymbol{\varepsilon}^{\boldsymbol{e}}}=(1-D) \mathbf{C}: \boldsymbol{\varepsilon}^{\boldsymbol{e}}$

$R=\rho \frac{\partial \psi}{\partial r}=Q[1-\exp (-b r)]$

$-Y=\rho \frac{\partial \psi}{\partial D}=-\frac{1}{2} \boldsymbol{\varepsilon}^{e}: \mathbf{C}: \boldsymbol{\varepsilon}^{e}$

With $R$ the isotropic hardening variable and $Y$ is elastic energy density release rate. The dissipation potential $F$ is defined by

$F=f+F_{D}$

where $f$ is the classical yield function described by means of the von Mises equivalent stress and that defines the effective von Mises stress $\tilde{\sigma}_{V M}$ as the variable. $F_{D}$ is the damage potential, which corresponds to the evolution of the damage law. These two functions are described by

$$
\begin{aligned}
& f=\tilde{\sigma}_{V M}-R-\sigma_{Y}=\sqrt{\frac{3}{2} \operatorname{dev}(\widetilde{\boldsymbol{\sigma}}): \operatorname{dev}(\widetilde{\boldsymbol{\sigma}})}-R-\sigma_{Y} \\
& F_{D}=\frac{S}{(1-D)\left(s_{0}+1\right)}\left(\frac{Y}{S}\right)^{S_{0}+1}
\end{aligned}
$$


where $\sigma_{y}$ is the initial yield stress, $\operatorname{dev} \tilde{\sigma}$ is the effective deviatoric stress tensor, $s_{0}$ is the damaged material constant and $S$ the damage strength. The damaged plastic strain is accumulated as $r=\int_{0}^{t}(1-D) \sqrt{\frac{2}{3} \dot{\boldsymbol{\varepsilon}}^{p}: \dot{\boldsymbol{\varepsilon}}^{p}} \mathrm{~d} t$ where $\dot{\boldsymbol{\varepsilon}}^{p}$ represents the plastic strain rate tensor and $t$ is the time variable.

Based on the definition of the function $F$ the evolutions of internal variables are expressed by:

$$
\begin{aligned}
& \left\{\begin{array}{l}
\dot{D}=\dot{\lambda} \frac{\partial F}{\partial Y}=\left(\frac{Y}{S}\right)^{s_{0}} \dot{p} \text { if } r>p_{D} \text { and } \chi=\frac{\operatorname{trace}(\widetilde{\boldsymbol{\sigma}})}{3 \tilde{\sigma}_{V M}}>-\frac{1}{3} \\
\dot{D}=0 \text { if } r \leq p_{D} \text { or } \chi=\frac{\operatorname{trace}(\widetilde{\boldsymbol{\sigma}})}{3 \tilde{\sigma}_{V M}} \leq-\frac{1}{3}
\end{array}\right. \\
& \dot{\varepsilon}^{p}=-\dot{\lambda} \frac{\partial F}{\partial(-\boldsymbol{\sigma})}=\frac{\dot{\lambda}}{1-D} \frac{3}{2} \frac{\operatorname{dev} \boldsymbol{\sigma}}{\sigma_{V M}} \\
& \dot{r}=-\dot{\lambda} \frac{\partial F}{\partial R}=\dot{\lambda}=\dot{p}(1-D)
\end{aligned}
$$

Where $p_{D}$ is the damage accumulated plastic strain threshold, $\chi$ is the triaxiality factor [24] and $\dot{\lambda}$ the plastic multiplier, which is determined by the consistency condition $(f=0$ and $\dot{f}=0)$.

Therefore 9 parameters should be identified, as listed in Table 1. These parameters are divided into four categories: characterizing the elasticity, plasticity, damage and fracture mechanisms.

Table 1: Materials parameters.

\begin{tabular}{cll}
\hline Parameters & Definition & Mechanisms \\
\hline $\boldsymbol{V}$ & Young's modulus & Elasticity \\
$\boldsymbol{\sigma}_{\boldsymbol{Y}}$ & Poisson ratio & Elasticity \\
$\boldsymbol{Q}$ & Saturation value (Voce hardening law) & Plasticity \\
$\boldsymbol{b}$ & Hardening exponent (Voce hardening law) & Plasticity \\
$\boldsymbol{p}_{\boldsymbol{D}}$ & Accumulated plastic strain threshold & Plasticity \\
$\boldsymbol{S}$ & Damage strength (Lemaitre denominator parameter) & Damage \\
$\boldsymbol{s}_{\mathbf{0}}$ & Damaged material constant (Lemaitre exponent parameter) & Damage \\
\hline
\end{tabular}


To obtain realistic and predictive simulations, accurate parameters are introduced in the behavioral law. For that reason, an estimation and validation procedure will be proposed to identify the ductile damage model parameters.

\section{II.2. Calibration methods of the coupled damage-plasticity model}

The idea is to compare an experimental Micro InDef test and a numerical version (FEM) of the same test. More precisely we compare the experimental and the numerical forming forces on $\mathrm{Z}$ axis. The material parameters are estimated in order to minimize the difference between these two forces.

As shown in Fig. 2, the procedure is divided in 2 steps. First step (initialization) is the identification of the elastic and plastic parameters by comparing results between tensile testing and modeling. The result of first step then used as input data for the second step (estimation), which is identification of plastic and damage parameters by comparing forming forces between Micro InDef testing and modeling. 


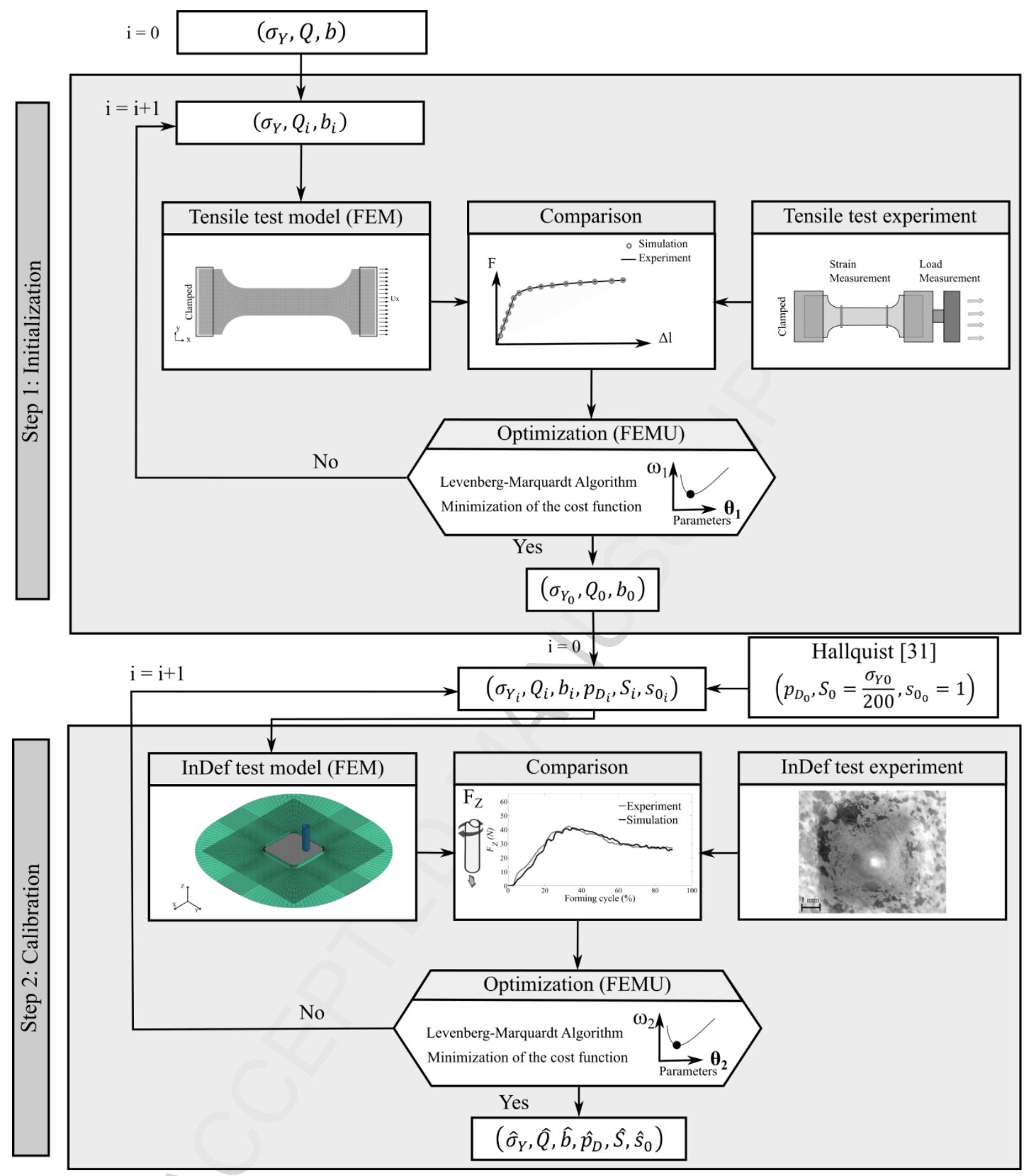

Fig. 2: Flowchart associated with the calibration of the coupled damage-plasticity model.

\section{II.2.1. Tensile test (Step 1)}

The first step comprise of experimental and numerical procedure. On the experimental procedure, uniaxial tensile tests are performed on flat specimens, which are generally cut from a metallic strip. All tests are performed at room temperature and quasi-static speed condition using an MTS electro-mechanic testing machine. Specimen geometry and the associated parameters are defined in Fig. 3. Due to the initial strip width, it 
is not possible to use standard specimen. However, the specimen geometry is close to the standard geometry by reducing the dimensions as defined in Fig. 3.

The measurements of the elongation $\Delta l$ were performed using a laser extensometer. Three tests are conducted in such a way to minimize experimental deviation.
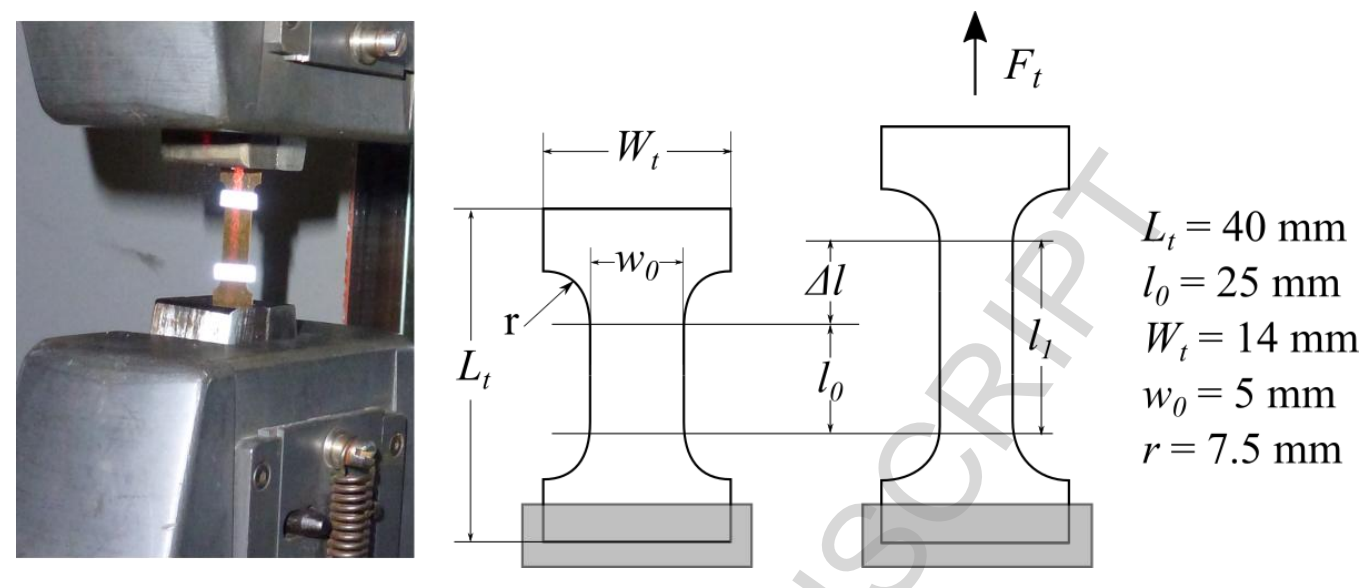

Fig. 3: Elongation of specimen due to tensile testing

A finite element parametric model is used to simulate tensile test. The specimen is meshed by 4 nodes quadrilateral shell elements in order to decrease the computational time. For this test, the left boundary is fixed while the right boundary is moved in the $\mathrm{x}$-direction, as shown in Fig. 4. The total reaction force is calculated by summing all nodal forces in $\mathrm{x}$ direction at the fixed end.

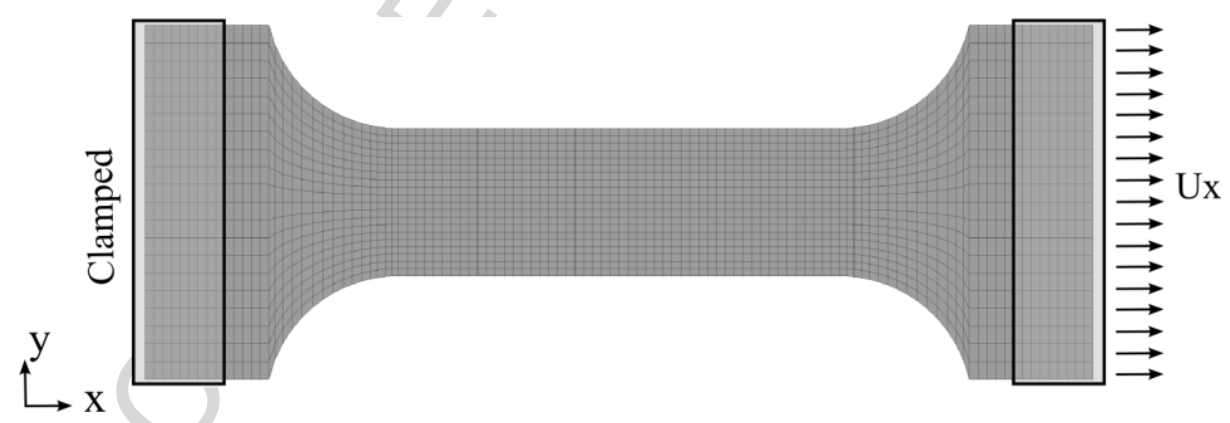

Fig. 4: Finite element modeling of tensile test.

The first step is dedicated to determinate the initial hardening parameters set $\left(\sigma_{y_{0}}, Q_{0}, b_{0}\right)$ by using tensile test. In the first approach, this step is necessary to start the identification (step 2) from a physically solution and to reduce the computation time.

The determination of the initial hardening parameters for the tensile test is realized using the FEMU method. Then, the numerical reaction force is compared to the experimental measurement and the hardening parameters 
are adjusted iteratively using an optimization algorithm. In order to avoid the necking phenomenon, only the experimental data until $23 \%$ of deformation are considered.

In the current study, the cost function $\omega_{1}\left(\boldsymbol{\theta}_{1}\right)$ is defined as the gap between the measured tensile force $F_{E}(t)$, and that obtained through the simulation, $F_{N}\left(\boldsymbol{\theta}_{1}, t\right)$.

$\omega_{1}\left(\boldsymbol{\theta}_{1}\right)=\frac{1}{N_{1}} \sum_{i=1}^{N_{1}}\left[F_{E}\left(t_{i}\right)-F_{N}\left(\boldsymbol{\theta}_{1}, t_{i}\right)\right]^{2}$

Where $N_{1}=600$ is the number of experimental points (until 23\%), which is equally distributed over the time interval $\left[\mathrm{t}_{1}, \mathrm{t}_{N_{1}}\right]$, and $\boldsymbol{\theta}_{1}$ is the vector of material parameters. The inverse method controls the three hardening parameters, $\widehat{\boldsymbol{\theta}}_{1}={ }^{T}\left(\hat{\sigma}_{y}, \widehat{Q}, \widehat{b}\right)$ which minimize this cost function. The minimization problem can be written formally as:

$\widehat{\boldsymbol{\theta}}_{1}=\arg \min _{\boldsymbol{\theta}_{1} \in\left[\boldsymbol{\theta}_{1}^{-}, \boldsymbol{\theta}_{1}^{+}\right]} \omega_{1}\left(\boldsymbol{\theta}_{1}\right)={ }^{T}\left(\hat{\sigma}_{y}, \widehat{Q}, \hat{b}\right)$

Where $\boldsymbol{\theta}_{1}^{-}$and $\boldsymbol{\theta}_{1}^{+}$are the minimum and maximum limits of the material parameters. A constrained optimization algorithm based on the Levenberg-Marquardt method [25-26] is used to solve the problem described by Eq. (18) in the MIC2M software [27].

\section{II.2.2. Micro Incremental Deformation (Micro InDef) test (Step 2)}

The Micro InDef testing device is illustrated in Fig. 5 is composed of a fixed die support, a modular die, a fixed blank holder clamped to the die using screws and a forming tool with a radius of $1 \mathrm{~mm}$ (hemispherical end tool). The lubrication of the sheet/tool interface (water/oil mixture) is used to improve the sheet formability. The tool moves with a constant feed rate of $500 \mathrm{~mm} / \mathrm{min}$ and rotates with a constant speed rate of $1000 \mathrm{rpm}$ to ensure the spindle integrity and reduce the effects of friction. 3-axis micro-milling CNC Machine (KERN) is used and the forming forces $\mathbf{F}_{\mathbf{e x p}}$ are acquired by using a 4-axis dynamometer (Kistler 9272). In the case of conventional incremental sheet forming this approach was used by Duflou et al. [13] and Ambrogio et al. [28] and micro-SPIF by Ben Hmida et al. [9]. As for the tensile ones, each test is repeated three times to ensure that the test is reliable. 


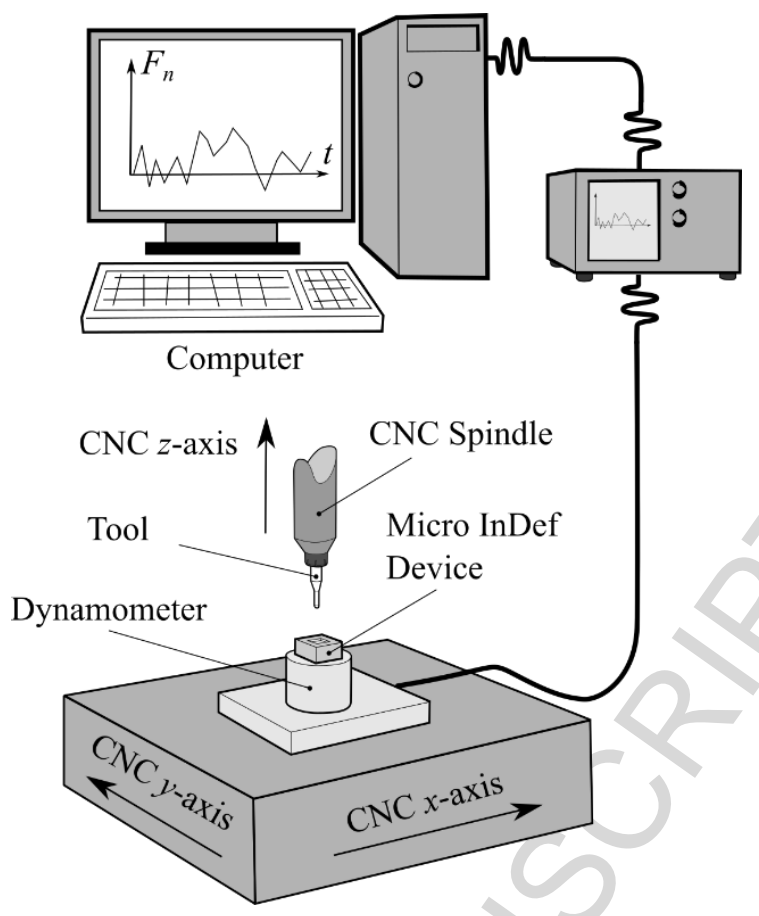

Fig. 5: Micro InDef testing device, forces acquisition principle $\left(\mathbf{F}_{\mathbf{e x p}}\right)$.

Pyramidal shape, with a draft angle $\alpha$, is used to perform the Micro InDef test. The geometrical definition of this shape is given in Fig. 6.

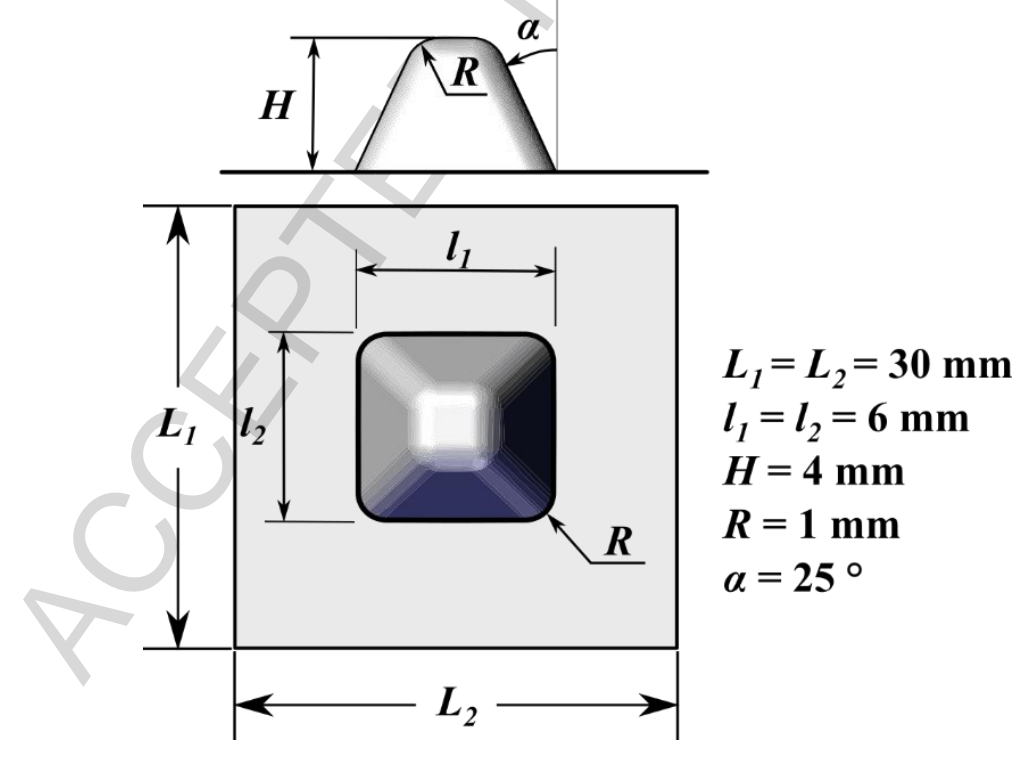

Fig. 6: Definition of the pyramidal part shape.

A particular attention is given to generate the tool path required to induce plastic deformation of the material and recover as much information as possible. Indeed, two approaches are used: the helical paths (continuous path) and the constant Z-level one (discontinuous path). Both strategies are illustrated in Fig. 7. 


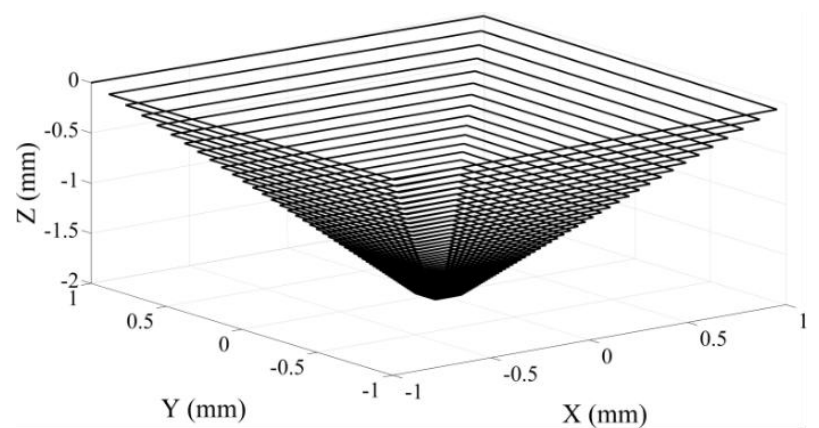

(a)

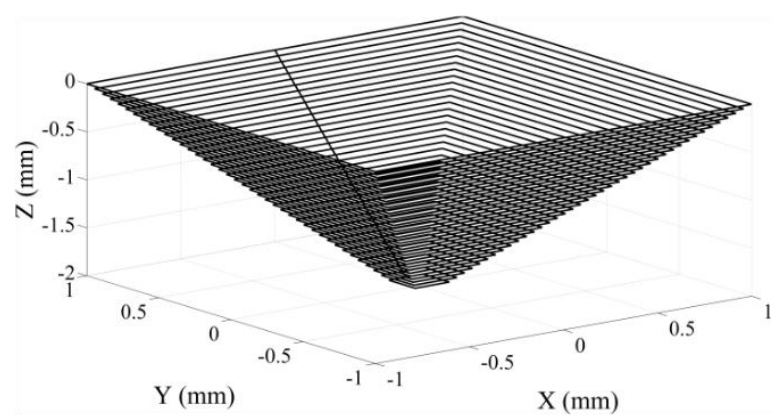

(b)

Fig. 7: Forming strategies: (a) helical, (b) constant Z-level.

A fully parametric toolbox, programmed in MATLAB language, has been developed to prepare the input files necessary for the simulation of the Micro InDef test (mesh, boundary, load and initial conditions, material behavior). This numerical toolbox was completely detailed and validated in the study proposed by Thibaud et al. [29]. The associated finite element mesh is presented below in Fig. 8.

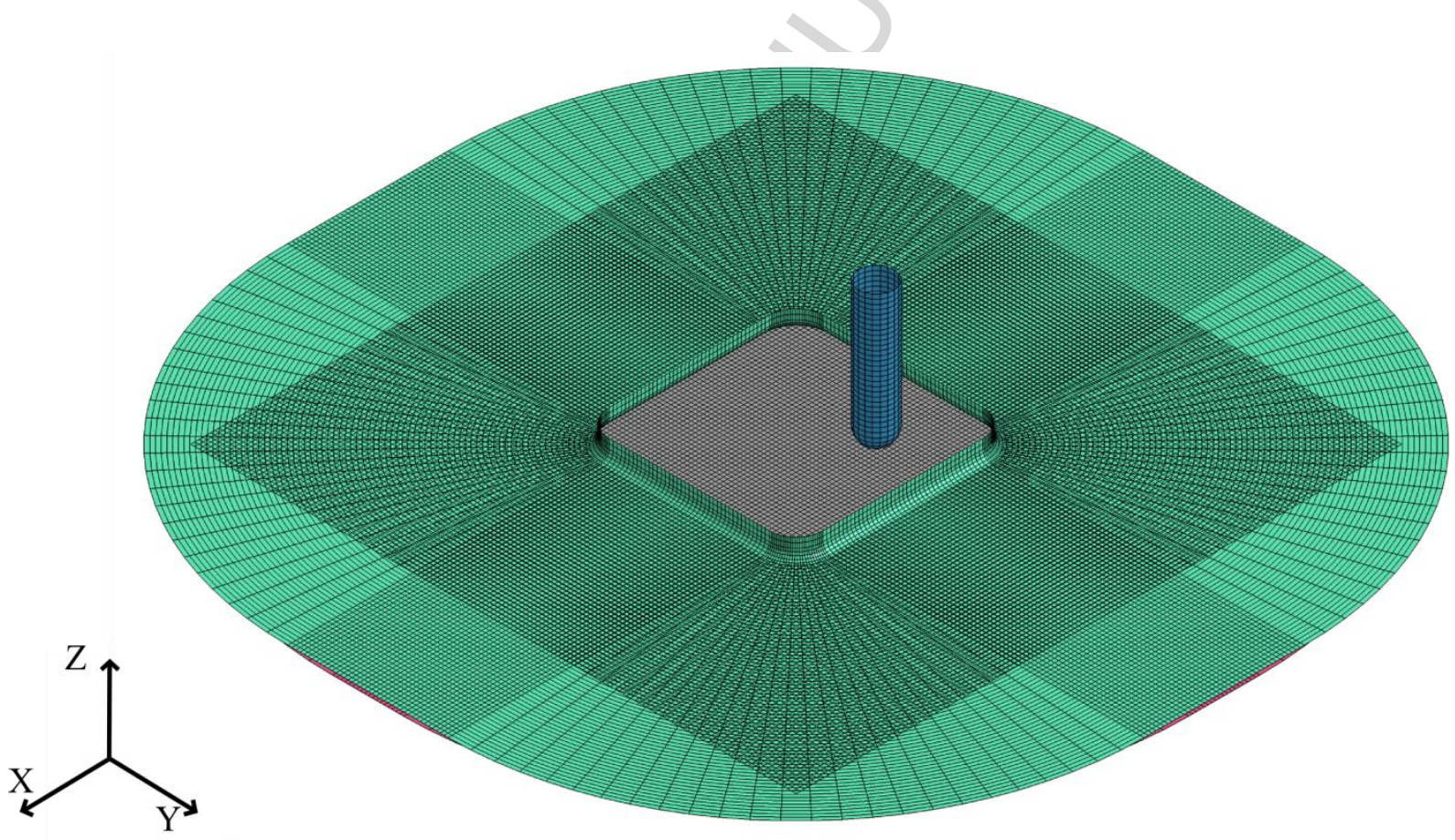

Fig. 8: Mesh model for InDef test simulations.

The blank is meshed with 8-nodes fully integrated solid elements and tools with 4-nodes rigid shell elements. To better predict the combined stress states (tension, bending, through-the-thickness shear TTS), two, three, five and ten elements in the blank thickness are tested. Starting from three elements, no significant difference in terms of stress (TTS) and forming forces are noted. Three elements are then considered in the blank thickness (6 
integration points through the thickness). 120 elements are imposed upon the length and width to discretize the blank with a total of 43200 solid elements.

The tool and the blank are modeled with the same geometrical parameters as in the experimental test. During simulation tests, the sheet is clamped along its edges, i.e. each node of the contour is fixed. The LS-DYNA software with an explicit integration method is used to simulate the InDef test. To decrease the computational time, the virtual simulation time is scaled down by a factor of 125 , in which the ratio of the kinetic energy to the total internal energy can be controlled within $1 \%$ to ensure a quasi-static forming process. Finally, a virtual simulation time of $0.2 \mathrm{~s}$, equivalent to a tool feed rate of $1200 \mathrm{~mm} / \mathrm{s}$, has been selected.

The coupled damage-plasticity model used for this simulation represents the main mechanisms of inelastic behavior, including plastic deformation, the change of elastic response and the localized failure, is used. This model was explained II.2.

The friction law chosen to simulate the tribological behavior at the interfaces between tools and the blank is a Coulomb's friction law, with a friction coefficient equal to 0.2 . This choice derives from studies proposed by Thibaud et al. [29] on the influence of friction on forming forces level and on numerical convergence. The number of integration points for shell elements in tensile tests and for solid elements in Micro InDef tests are completely discussed in these studies.

From the numerical point of view, when damage variable has higher value than critical damage $\left(D>D_{c}\right)$ in an integration point of an element, it is deleted from the mesh. In the case of the fracture prediction, the mesh density is determined to be sufficient for the process simulations.

When finite elements are deleted, blank loose some mass. But from the identification procedure, this phenomenon is not considered because all identified parameters are already obtained. So there is no influence on the identification method. When fracture occurs, it will be necessary to predict fracture evolution by introducing a more complex approach as the X-FEM method proposed by Moës et al. [30]. in dynamic mode and it will be possible to identify fracture evolution by the identification procedure but it is not the objective of this paper. This step consists of simulating a Micro InDef test, whose results (forming force) are sensitive to the material parameters that we want to adjust. The test is first simulated with a set of initial parameters, considered to be physically acceptable. Then, the numerical results are compared to the experimental measurements and the material parameters are adjusted iteratively using the same optimization algorithm as on tensile test. The inverse 
analysis is then performed using the smooth profile to avoid the signal noise of the z-axis forming force without any loss of information.

The values of the plastic parameters $\left(\sigma_{y_{0}}, Q_{0}, b_{0}\right)$ identified from tensile test are introduced as the initial values in this second step. The initial values of the accumulated plastic strain threshold $p_{D_{0}}$, the damage strength $S$ and the damaged material constant $s_{0}$ are introduced in relation with the proposition of Hallquist [31].

Here, the cost function $\omega_{2}\left(\boldsymbol{\theta}_{2}\right)$ is defined as the gap between the axial forming forces obtained through the experiments $F_{Z E}(t)$ and those obtained through the simulation, $F_{Z N}\left(\boldsymbol{\theta}_{2}, t\right)$ of Micro InDef test with the helical strategy.

$\omega_{2}\left(\boldsymbol{\theta}_{2}\right)=\frac{1}{N_{2}} \sum_{i=1}^{N_{2}}\left[F_{Z E}\left(t_{i}\right)-F_{Z N}\left(\boldsymbol{\theta}_{2}, t_{i}\right)\right]^{2}$

Where $N_{2}=1000$ is the number of experimental points, which is equally distributed over the time interval $\left[\mathrm{t}_{1}, \mathrm{t}_{N_{2}}\right]$, and $\boldsymbol{\theta}_{2}$ is the vector of material parameters. Six parameters associated with plasticity and damage mechanisms $\widehat{\boldsymbol{\theta}}_{2}={ }^{T}\left(\hat{\sigma}_{y}, \hat{Q}, \hat{b}, \hat{p}_{D}, \hat{S}, \hat{s}_{0}\right)$ which minimize this cost function, are thus estimated. The critical damage parameter $D_{c}$ is estimated after the minimization procedure by detecting the moment of the experimental fracture.

For each iteration of the calibration procedure, if $n$ represents the number of parameters to identify, it should be performed at least $n+1$ simulations. This is necessary to fulfill the optimization algorithm requirements.

Due to the significant size of the problem and the stability condition associated with the explicit algorithm, simulation time holds an important role, for this study one simulation requires approximately 8 hours. The massively parallel processing (MPP) version of LS-DYNA is used with 16 processors to decrease the computational time.

\section{II.3. Validation tests}

Some validation tests are also performed and presented in this section in order to evaluate the efficiency of the identified model under different stress triaxiality.

A validation procedure is carried out to verify the quality of the calibrated model. Firstly, the geometry of the experimental part is compared with the geometry of the part obtained with the finite element simualation. The experimental part is digitalized using a non-contact 3D laser scanning system (Steintek Mobilescan 3D) in high resolution mode. This optical method provides a high density of measured points (more than 100,000) with a 
resolution of less than $0.01 \mathrm{~mm}$ and an accuracy of $5 \mu \mathrm{m}$. The comparison with the numerical shape requires the extraction of the outer surface mesh. The experimental data (measured points) are then compared with this outer mesh using inspection software (Geomagic Qualify). Secondly, four validation tests are done, as presented in Fig. 9.

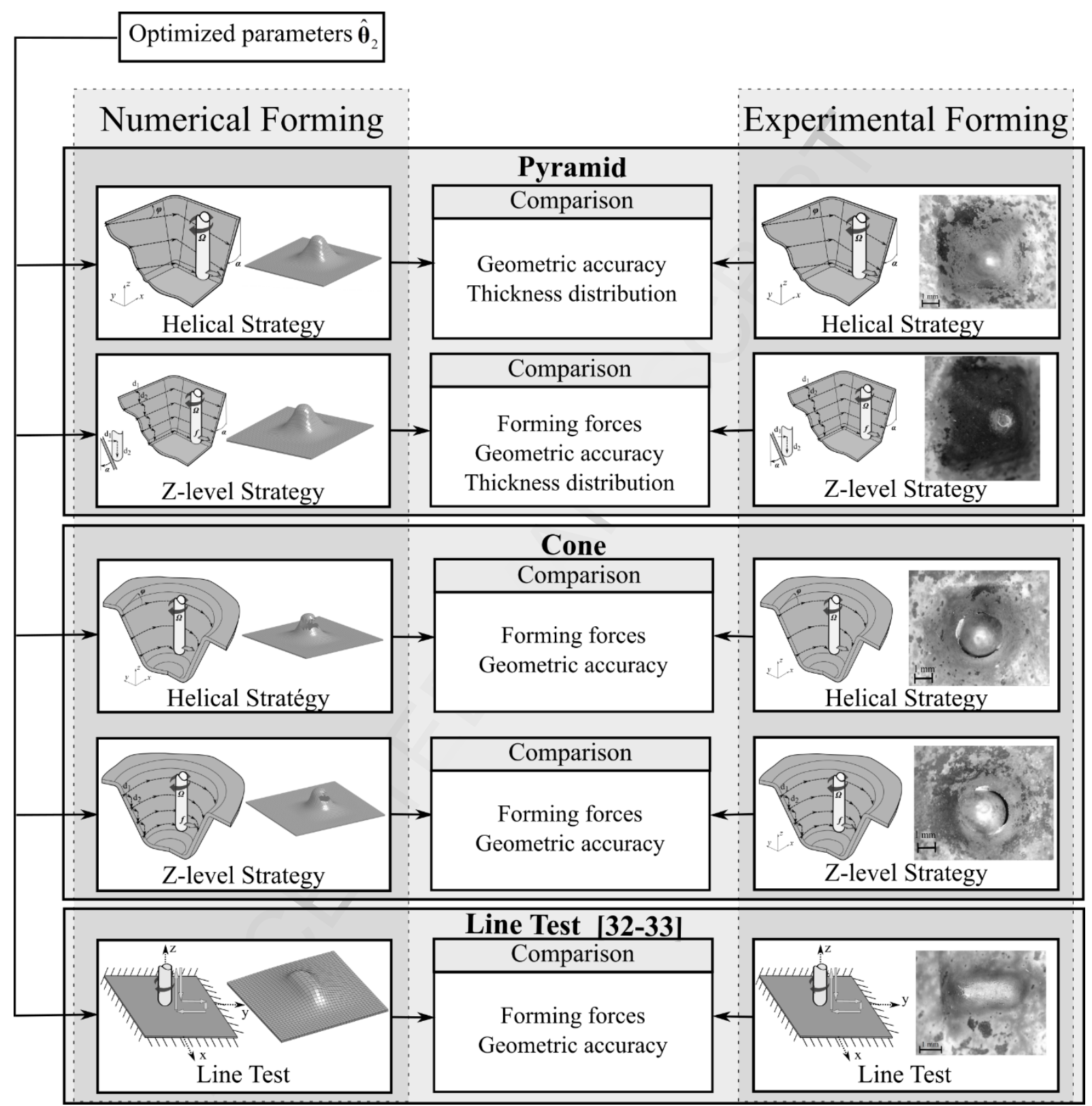

Fig. 9: The validation procedure of the coupled damage-plasticity constitutive behavior.

The coupled damage-plasticity model identified with the helical strategy and pyramidal geometry with the procedure defined previously is used to simulate: 
- a pyramidal-shaped part using the Z-level strategy. In this case, the forming path and the strain mode are different compared to the helical strategy. Consequently, the strain mode represented by the triaxiality factor is different for both forming strategies.

- a conical shaped part using both forming strategies (helical and Z-level strategies). The geometric dimensions of this new shape part are chosen in such a way that a fracture occurs. It is then possible to validate all the material parameters including the critical damage parameter $D_{c}$.

- $\quad$ a line test : the principle consists of locally deforming a blank, following a dedicated path. The initial tool position is tangent to the top surface of the sheet and then it follows the path described in Fig 10. Similar test has already been reported by Henrard et al. [12] , Bouffioux et al. [32] and Guzman et al. [33].

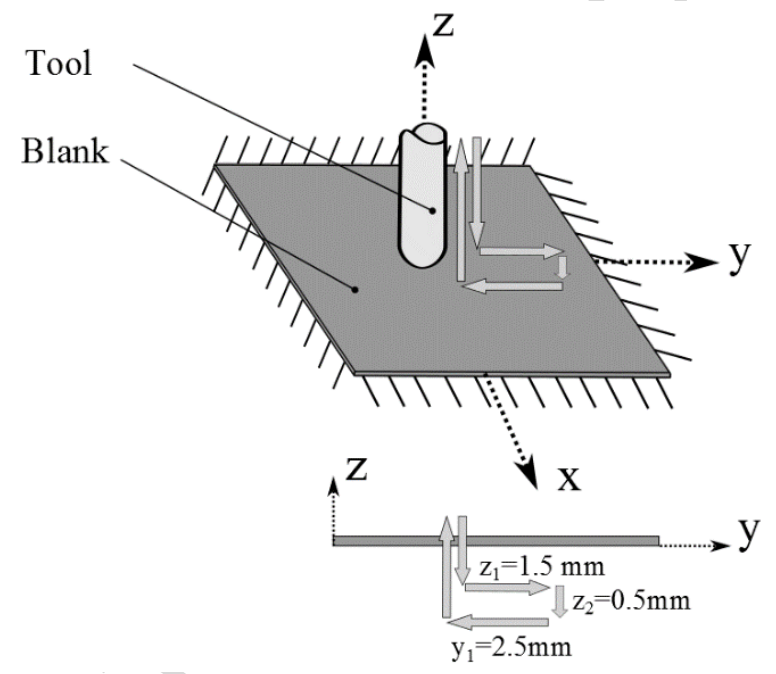

Fig. 10: Line test principle [32-33].

Finally, the results in terms of forming forces and geometric accuracy are compared to the experimental data.

To confirm the validation of the numerical model, local comparisons with experiments are carried out. The thickness is calculated by measuring the normal distance between the inner and outer surface of the sheet over the whole specimen by cutting it into two symmetric parts. Cutting is performed by wire electro-discharge machining process (WEDM) to avoid introducing any additional mechanical stresses to the part and the experimental data are obtained via optical metrology and image processing.

\section{II.4. Quantification of information richness from forming force}

An identifiability analysis should be systematically conducted to ensure the parametric identification problem is well-posed, the robustness of the FEMU method and the physical significance of the parameters. By using a 
scalar criterion based on the collinearity and the norm of the sensitivity vectors of the forming force, this analysis allows for quantifying the information richness and the identifiability of all parameters' subset.

This type of analysis has already been applied in other disciplines that develop over-parameterized models, e.g., Brun et al. [34] and Gujarati [35] for the environmental simulation models and econometrics, respectively. Recently, Richard et al. [36] employed this technique to ensure the identifiability of the viscoelastic behavior from instrumented spherical indentation test.

In the current study, a criterion based on the sensitivity of the axial forming force is used to measure the parameter identifiability of the coupled damage-plasticity constitutive law.

To be locally identifiable, a parameter subset has to satisfy two conditions. First, the model output $F_{Z N}\left(\boldsymbol{\theta}_{2}, t\right)$ has to be sufficiently sensitive to individual changes of each parameter. Second, the collinearity of the dimensionless sensitivity functions of $F_{Z N}\left(\boldsymbol{\theta}_{2}, t\right)$ to material parameters has to be sufficiently low. These two conditions are quantified using a scalar identifiability index.

In general, sensitivity analysis is defined as the method of providing the influence of the variation of the optimization parameters (material, loading, geometry...) on the response of the finite element analysis (force, displacement, stress, strain...) via the integration of a behavioral model. The purpose is to determine the sensitivity of the numerical simulation of the axial forming force during the Micro InDef test for various input material parameters. The parameter sensitivities are computed using the backward finite difference method. The components of the dimensionless sensitivity matrix $\mathbf{S}$ are mathematically defined by:

$S_{i j}=\frac{\theta_{2 j}}{F_{Z N, \text { max }}} \frac{\partial F_{Z N}\left(\boldsymbol{\theta}_{2}, t_{i}\right)}{\partial \theta_{2 j}}$

For computing this matrix, the optimization software MIC2M is used and a sensitivity ranking is performed by means of the following relation:

$\delta_{j}=\frac{1}{N} \sum_{i=1}^{N}\left|S_{i j}\right|$

where $N$ is the number of measurement points. The sensitivity ranking measures the mean sensitivity of the simulated z-axis forming force to a variation of the parameter value $\theta_{2 j}$. A high $\delta_{j}$ means that the value of the parameter $\theta_{2 j}$ has an important influence on the simulation result, while a value of zero indicates that the simulation result does not depend on the parameter $\theta_{2 j}$.

A local identifiability index $I_{K}$ of parameter subset $K$ can be written as follows [36]: 
$I_{K}=\log _{10}\left(\frac{\lambda_{\max }}{\lambda_{\min }}\right)$

$\lambda_{\max }$ and $\lambda_{\min }$ are the largest and the smallest eigenvalue of the dimensionless pseudo-hessian matrix $\mathbf{H}$, respectively. The $\mathbf{H}$ matrix is estimated from a dimensionless sensitivity matrix (defined for a subset $K$ of parameters) by the following relation:

$\mathbf{H}=\mathbf{S}^{\mathrm{T}} \mathbf{S}$

According to Gujarati [35], $I_{K}$ smaller than 2 are considered as having high identifiability, while a value above 3 indicates a low identifiability.

The $I_{K}$ index is computed for all the subsets of the parameter space and reveals all the identifiable sets of parameters $\left(I_{K}<3\right)$ by quantifying the richness of the used data.

The sensitivity $\delta_{j}$ (Eq. (21)) and identifiability index $I_{K}$ (Eq. (22)) are local measurements whose results depend on the material parameter values. Some validation tests are also performed and presented in the next section in order to evaluate the efficiency of the identified model under different stress triaxiality.

Although in this study the identifiability analysis was done after the FEMU method, but it is important to note the possibility of doing this analysis before FEMU method with different values of $\theta$ and different types of trajectory.

\section{Results}

\section{III.1. Tensile test (Step 1)}

Plastic parameters $\left(\sigma_{y_{0}}, Q_{0}, b_{0}\right)$, which are calibrated via a tensile test, are presented in Table 2 . The comparison between the hardening model response and the experimental load-displacement curve is given in Fig. 11. The model is in good agreement with the experimental curve.

Table 2: Material parameters calibrated from tensile test.

\begin{tabular}{ccc}
\hline $\boldsymbol{\sigma}_{\boldsymbol{y}_{\mathbf{0}}}$ & $\boldsymbol{Q}_{\mathbf{0}}$ & $\boldsymbol{b}_{\mathbf{0}}$ \\
\hline $69.07 \mathrm{MPa}$ & $184.66 \mathrm{MPa}$ & 16.14 \\
\hline
\end{tabular}




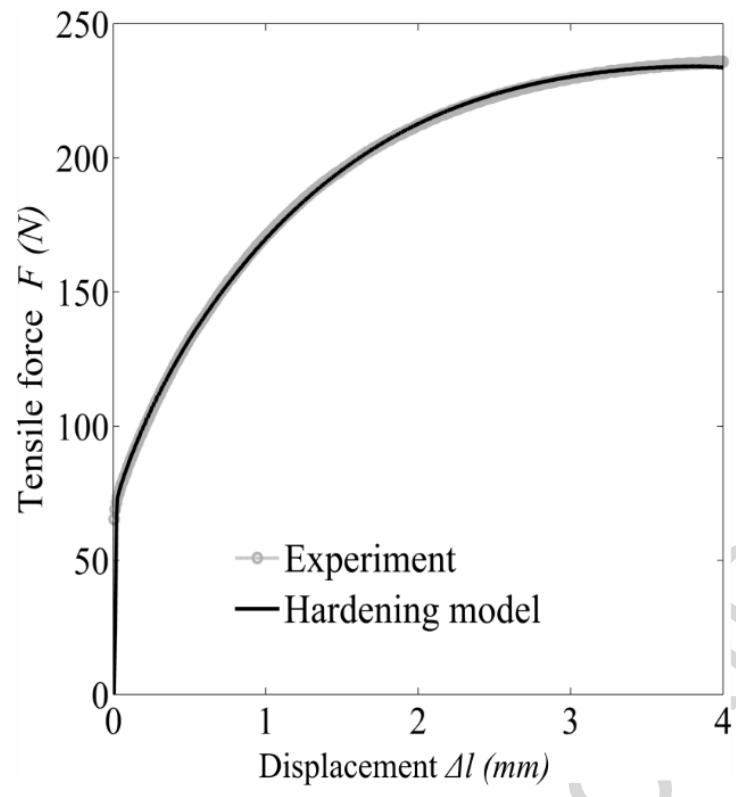

Fig. 11: Experimental and model comparisons of load-displacement tensile curves.

\section{III.2. Micro InDef test (Step 2)}

By using the parameters estimation from Micro InDef test, the parameters are obtained in eight iterations. The set of calibration parameters is summarized in Table 3 .

Table 3: Material parameters calibrated by using Micro InDef test

with helical strategy and pyramidal geometry.

\begin{tabular}{ccccccc}
\hline$\widehat{\boldsymbol{\sigma}}_{\boldsymbol{y}}$ & $\widehat{\boldsymbol{Q}}$ & $\widehat{\boldsymbol{b}}$ & $\widehat{\boldsymbol{p}}_{\boldsymbol{D}}$ & $\widehat{\boldsymbol{S}}$ & $\widehat{\boldsymbol{s}}_{\mathbf{0}}$ & $\widehat{\boldsymbol{D}}_{\boldsymbol{c}}$ \\
\hline $67.97 \mathrm{MPa}$ & $189.60 \mathrm{MPa}$ & 16.00 & 0.35 & $1.31 \mathrm{MPa}$ & 1.01 & 0.68 \\
\hline
\end{tabular}

The comparison between the numerical axial forming force $F_{Z}$ and the experimental one is presented in Fig. 12 . 


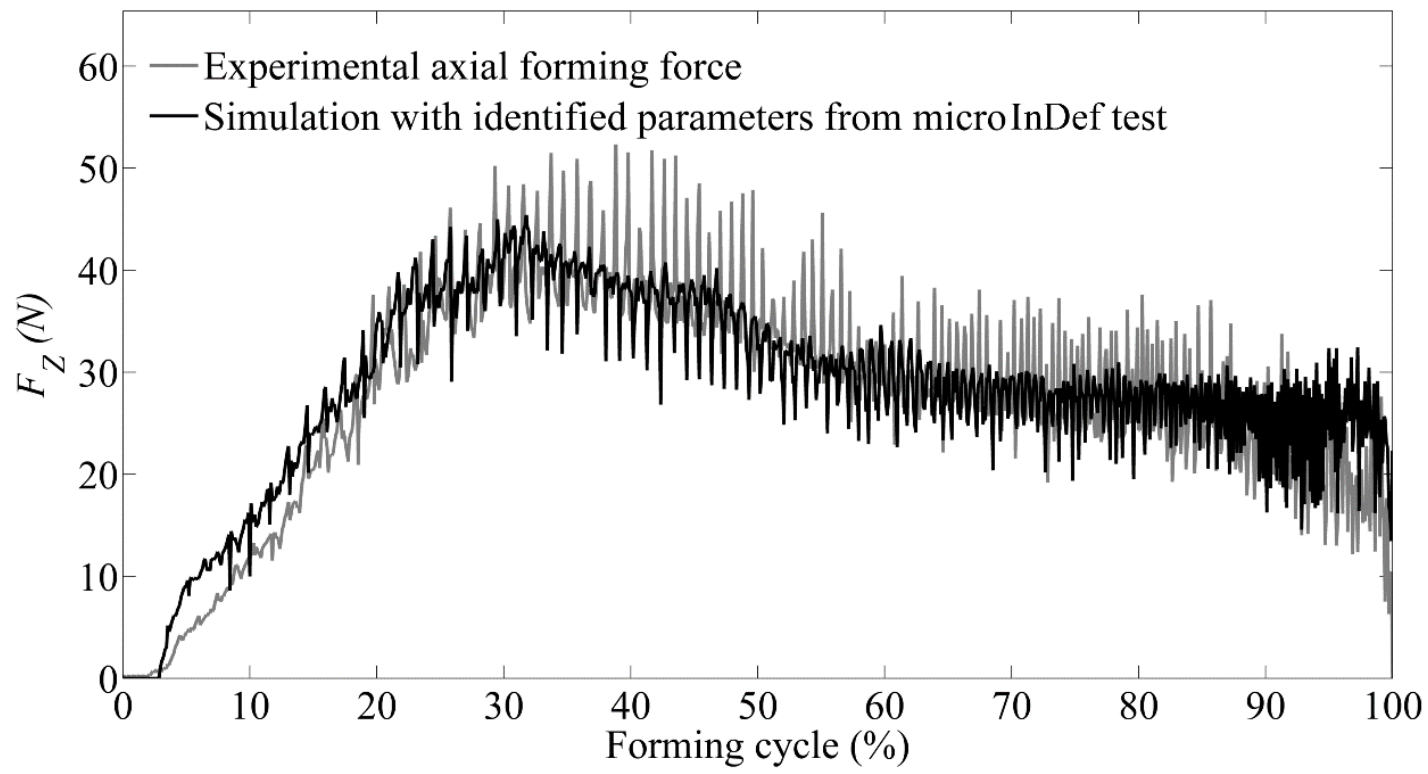

Fig. 12: Evolutions of numerical and experimental axial forming forces using the helical strategy and pyramidal geometry.

The evolution of the axial forming force is well represented, except at the beginning of the forming process. This difference is due to the initial geometrical defects (tools and part). When large strains occur, the evolution of the numerical process becomes close to the experimental data.

\section{III.3. Validation tests}

To validate the ductile damage model, a comparison between the final numerical geometry and the experimental one is carried out and given in Fig. 13. 


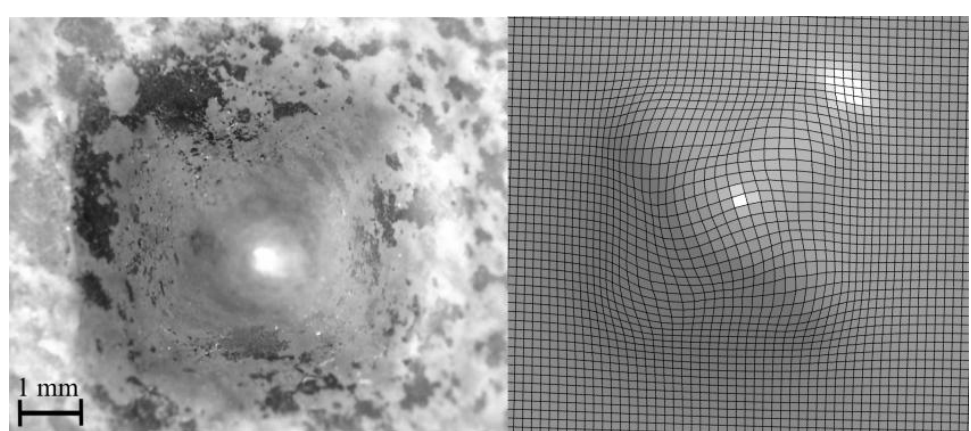

(a)

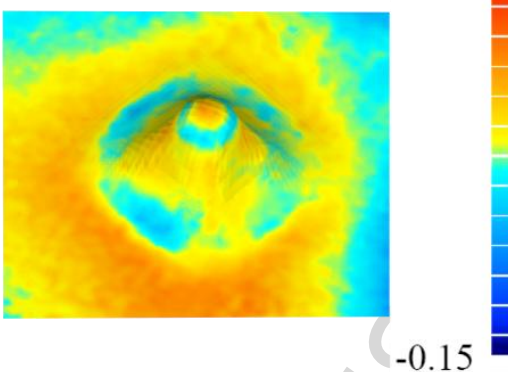

(b)

$\mathrm{mm}$

Fig. 13: Helical strategy: (a) experimental and numerical parts obtained using the helical strategy and pyramidal geometry, (b) 3D geometrical comparisons.

The obtained shapes can be considered far as the desired one (Fig. 6). Due to InDef test (dieless process) and the deformation path, it is not possible to obtain the desired part, as in milling operation for example, without define a modified toolpath. But in this case, it is not the objective because we want to define the same toolpath for experimental and numerical tests to identify mechanical behavior and not to obtain the desired part. This is why the experimental and numerical parts are compared and there is no comparison with the desired part.

The pyramidal shape obtained via simulation is close to the experimental part. The differences at the edges of the workpiece $( \pm 0.15 \mathrm{~mm})$ and at the base of the pyramid $(-0.06 \mathrm{~mm})$ can be explained as follows:

- it is easy to deform the experimental part away from the forming zone during handling due to its flexibility (very thin sheet);

- the value of the die radius and its position strongly influence the final shape. The actual die radius is not strictly identical to that used for the simulations. Moreover, this area is highly dependent on the springback effect, which is, again, a difficult parameter to control.

The comparison between the numerical model section and the experimental one is given in Fig. 14a, and the thickness evolution is plotted in Fig. 14b. 


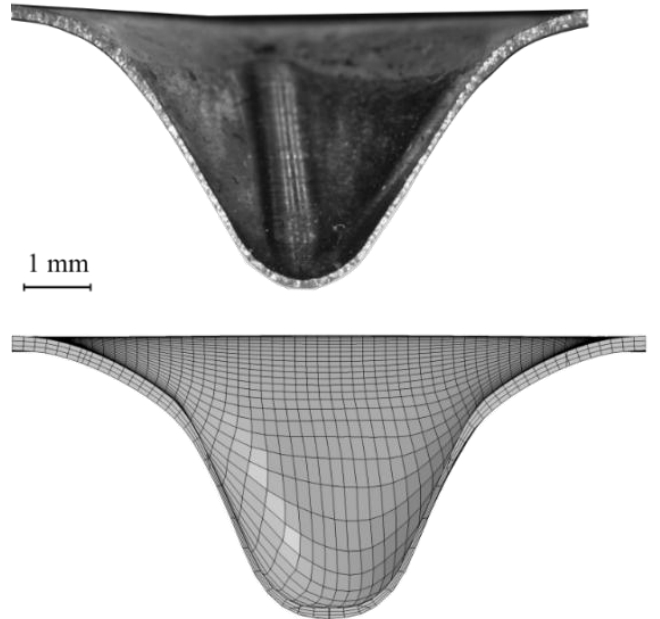

(a)

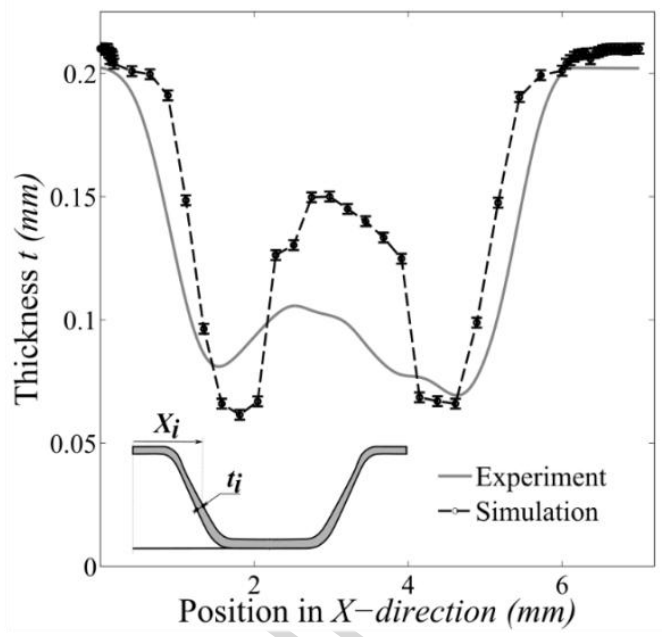

(b)

Fig. 14: Numerical and experimental comparisons: (a) section, (b) thickness evolution.

A good correlation between experiments and simulations can be noticed. The minimum value of the thickness is approximately $0.07 \mathrm{~mm}$, which corresponds to a thinning of $66 \%$.

The last part of the validation is devoted to the verification of the the ductile damage model predictability. The calibrated material parameters with the pyramidal geometry and helical strategy, presented in Table 3 , are used to simulate the tests explained in section II.3, namely, a pyramid shape obtained with a constant Z-level strategy, a truncated cone using two toolpaths and a line test.

Table 4 summarizes the comparisons between the forming forces, the thickness distributions and the final geometries obtained by numerical simulations and experiments.

In the case of the pyramid forming using a constant Z-level strategy, the evolution of the axial forming force prediction $F_{Z}$ is in good agreement with its experimental counterpart. The 3D geometrical comparison shows a good agreement between the experimental and FEM parts. The numerical and the experimental thickness evolutions are quite close with a minimum value of about $0.075 \mathrm{~mm}$.

For the conical shapes, the cracks appear from damage about of $60 \%$ that correspond to $94 \%$ and $85 \%$ of the forming cycle for helical and Z-level strategies, respectively.

The crack appearance can be detected from the significant decreasing of the force level toward zero. The variations of the force level (alternation between a null and a positive value) at the end of the forming process 
are due to the alternative contact between the tool and the blank (displacement with the cracked top of the pyramid).

Concerning the line test, the comparison of the forming forces and the geometric shapes also gives good results, which indicate a good agreement between both numerical and experimental data. It can be observed that in the first part of the line test, actually there is a difference about $15 \%$ due to experimental test but also from numerical considerations. First of all, at this scale, the blank is not perfectly flat and it exhibits a geometrical defects. For the experimental test, the contact and the reaction force are more important than the numerical ones. The second assumption is also based on the necessity to develop a more accurate friction law because the ratio between tool depth $z_{1}$ and the initial thickness $h_{0}=0.21 \mathrm{~mm}$ is equal to more than seven. In this case, it is clear than friction condition are more important. The pyramid angle is chosen to limit the influence of friction effects. In the case of the line test, it will be necessary to improve friction model.

A third assumption may be proposed and it is associated to boundary conditions. Due to the important tool depth, boundary condition defects influence greatly the elastic response. When plastic deformations occur, a more local response is observed and numerical simulation is close to the experimental test. 
Table 4: Validation tests.

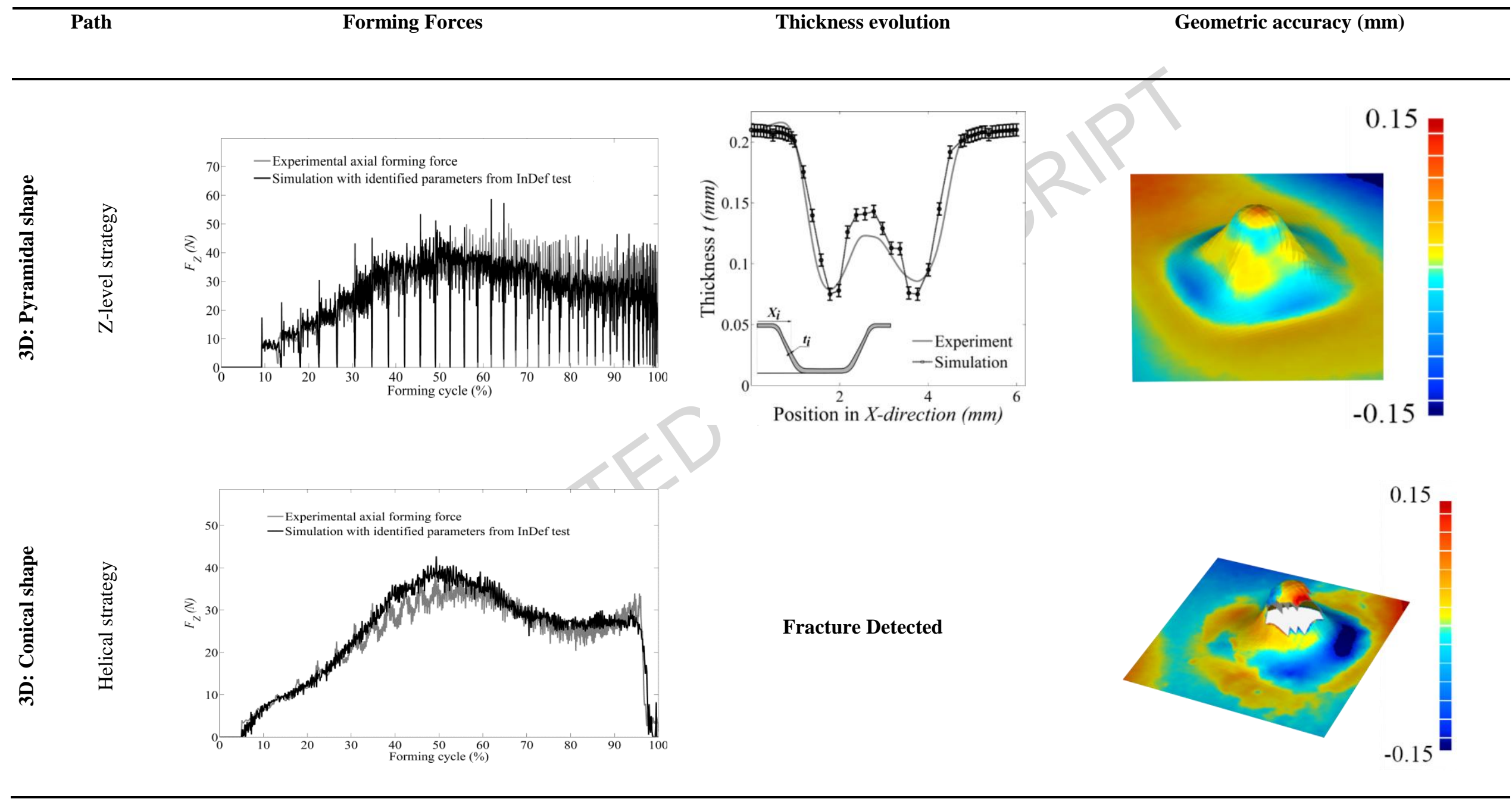




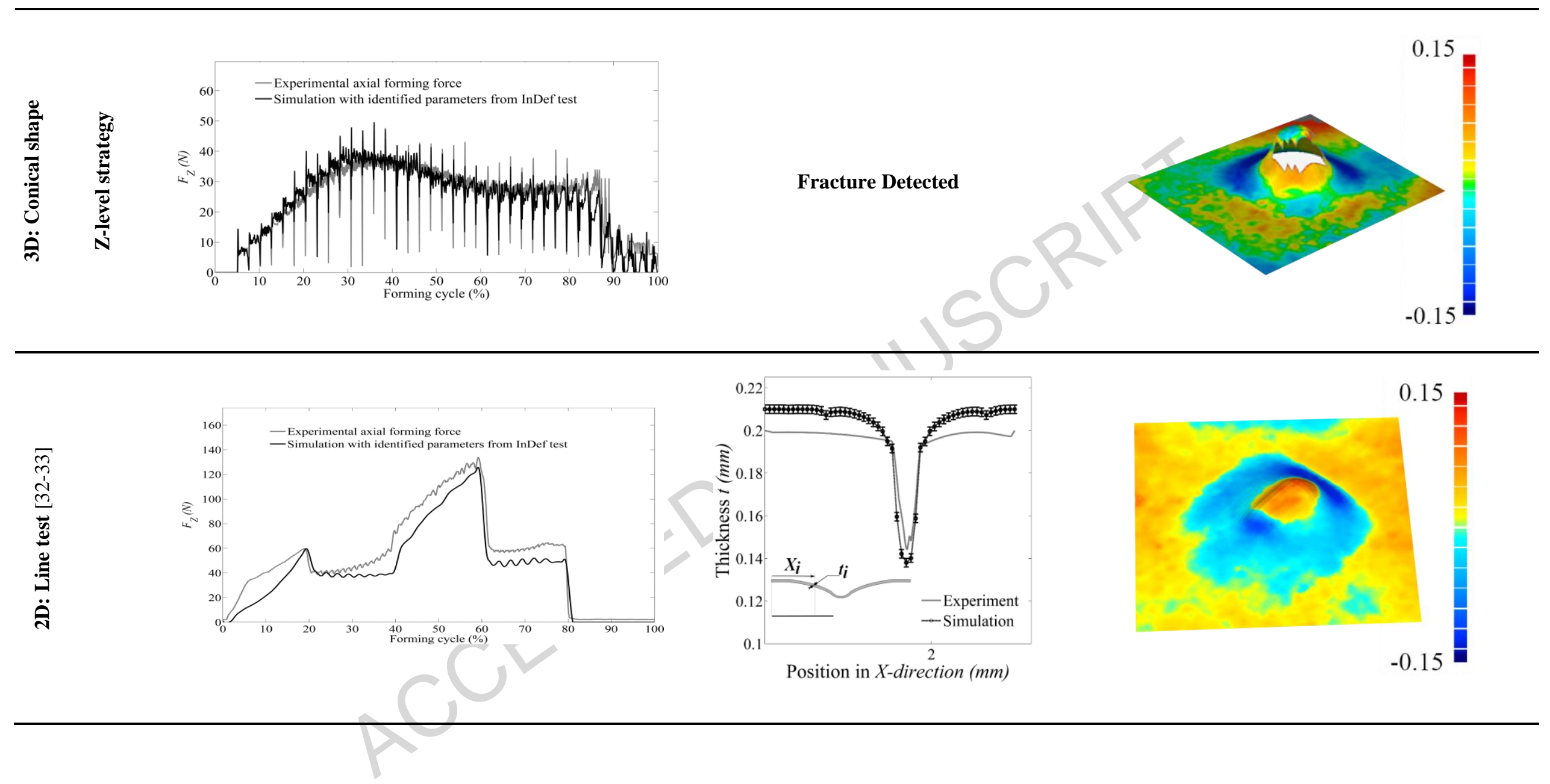




\section{III.4. Forming force information richness}

Fig. 15 shows the comparison of the average sensitivities $\delta_{j}$ of the forces (tensile force and axial forming force), defined by Eq. 21, to the plastic damage parameters during tensile test and Micro InDef test, using helical strategy and pyramidal geometry. It can be seen that the tensile force is sensitive to the plastic parameter variations but is very insensitive to the damage parameters. Concerning the axial forming force, it is important to note that all sensitivities are approximately of the same order of magnitude. This is a necessary condition (but not sufficient) for good conditioning of the parametric identification problem.

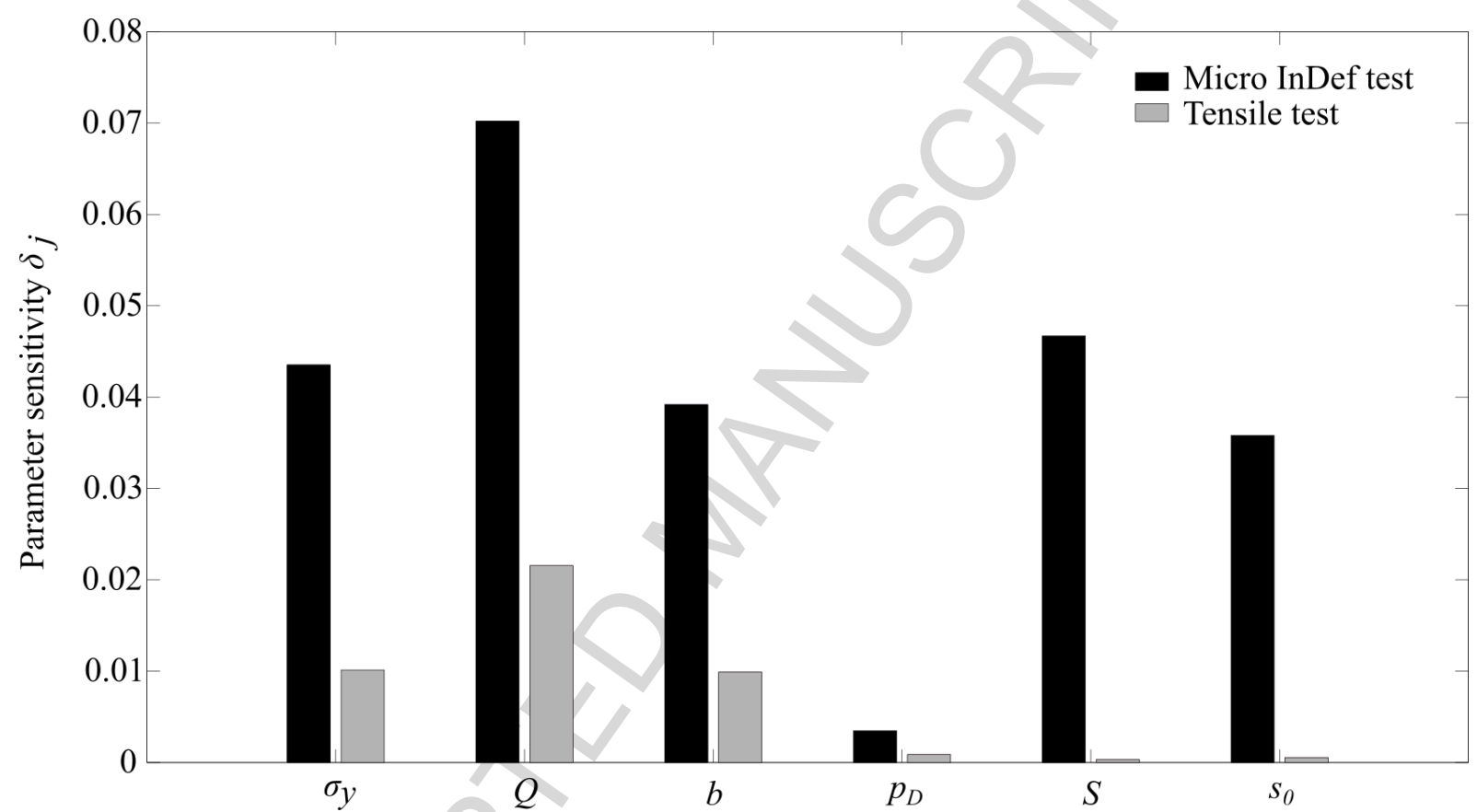

Fig. 15: Average sensitivities of the tensile force and the forming force to the plastic damage parameters using tensile and InDef tests (helical strategy and pyramidal geometry)

Fig. 16 shows the measurement of the identifiability index (Eq. 22) for three sets of parameters $K$ : plastic $\left(\hat{\sigma}_{y}, \hat{Q}, \hat{b}\right)$, damage $\left(\hat{p}_{D}, \hat{S}, \hat{s}_{0}\right)$ and plastic with damage $\left(\hat{\sigma}_{y}, \hat{Q}, \hat{b}, \hat{p}_{D}, \hat{S}, \hat{s}_{0}\right)$.

in the cases of the tensile and Micro InDef tests. In the case of tensile test, the $I_{K}$ values show that the plastic set of are identifiable $\left(I_{K}<2\right)$ and the damage parameters are weakly identifiable $\left(I_{K}>2\right)$. These results show the poverty of the experimental data obtained by the tensile test to identify the damage parameters. However, all the parameter sets lead to low values $\left(I_{K}<2\right)$ using the incremental deformation test with helical strategy. It can be then considered as a promising technique to accurately identify material in very large deformations. 


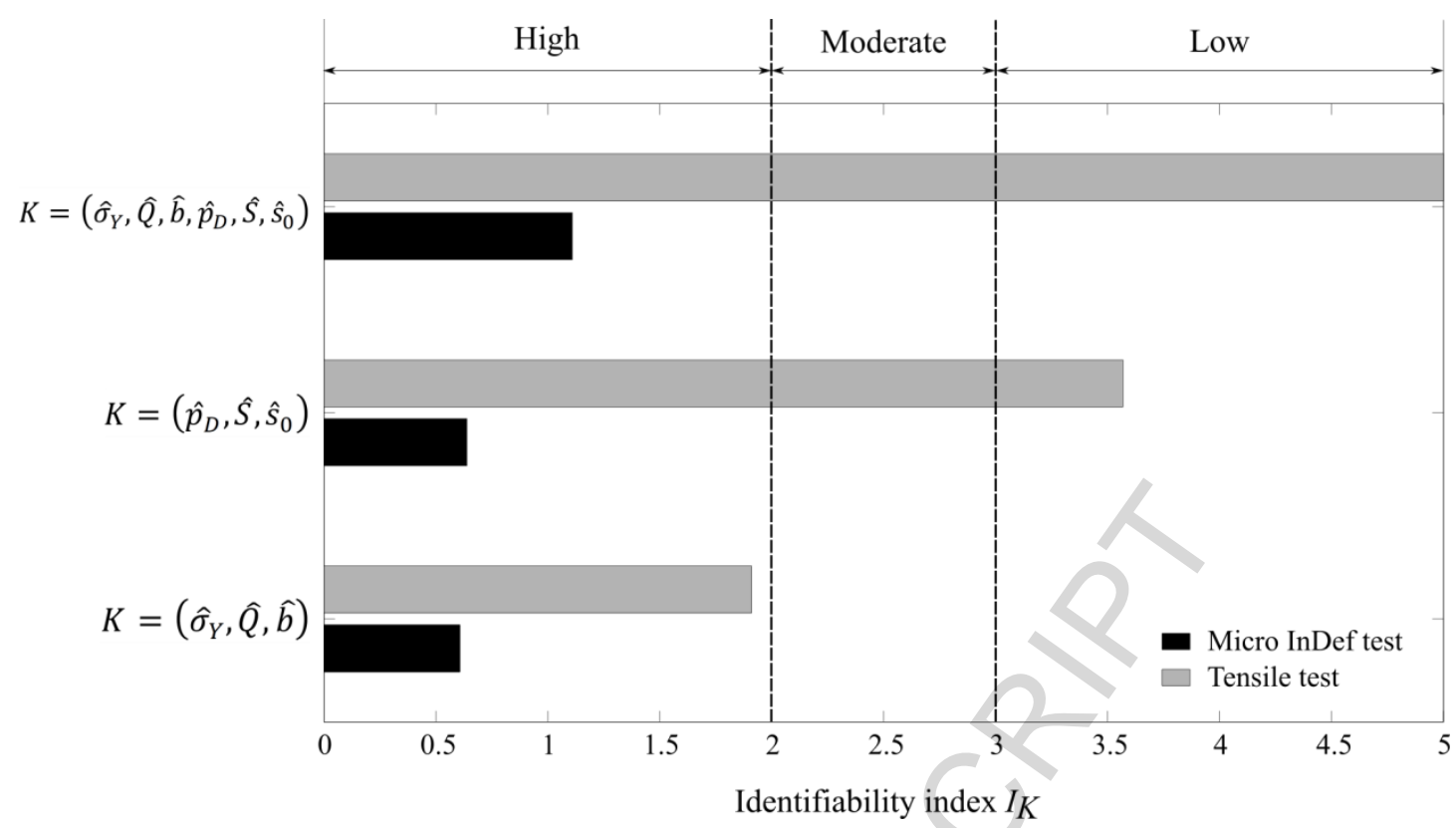

Fig. 16: Identifiability index using tensile test and InDef test (helical strategy and pyramidal geometry) for different parameters subsets $K$.

In order to see the identification areas for the different combinations of parameters, the evolution of $I_{K}$ with respect to the forming cycle is drawn, as presented in Fig. 17. Each parameter combination is identified when $I_{K}$ drops following a quasi-vertical slope down to a stabilized value less than 2 .

As shown in Fig. 17, the plastic $\left(\hat{\sigma}_{y}, \hat{Q}, \hat{b}\right)$ and damage $\left(\hat{p}_{D}, \hat{S}, \hat{s}_{0}\right)$ parameters can be identified respectively after about $18 \%$ and $35 \%$ of the forming cycle.

This result shows that, all the interesting information is in the first half of the forming path. As the richness of information is sufficient in this range, reducing identification time is possible. For determining the fracture parameter, it is necessary to use the complete evolution of axial forming path, but it's possible to change the toolpath in order to accelerate the fracture occurrence. 


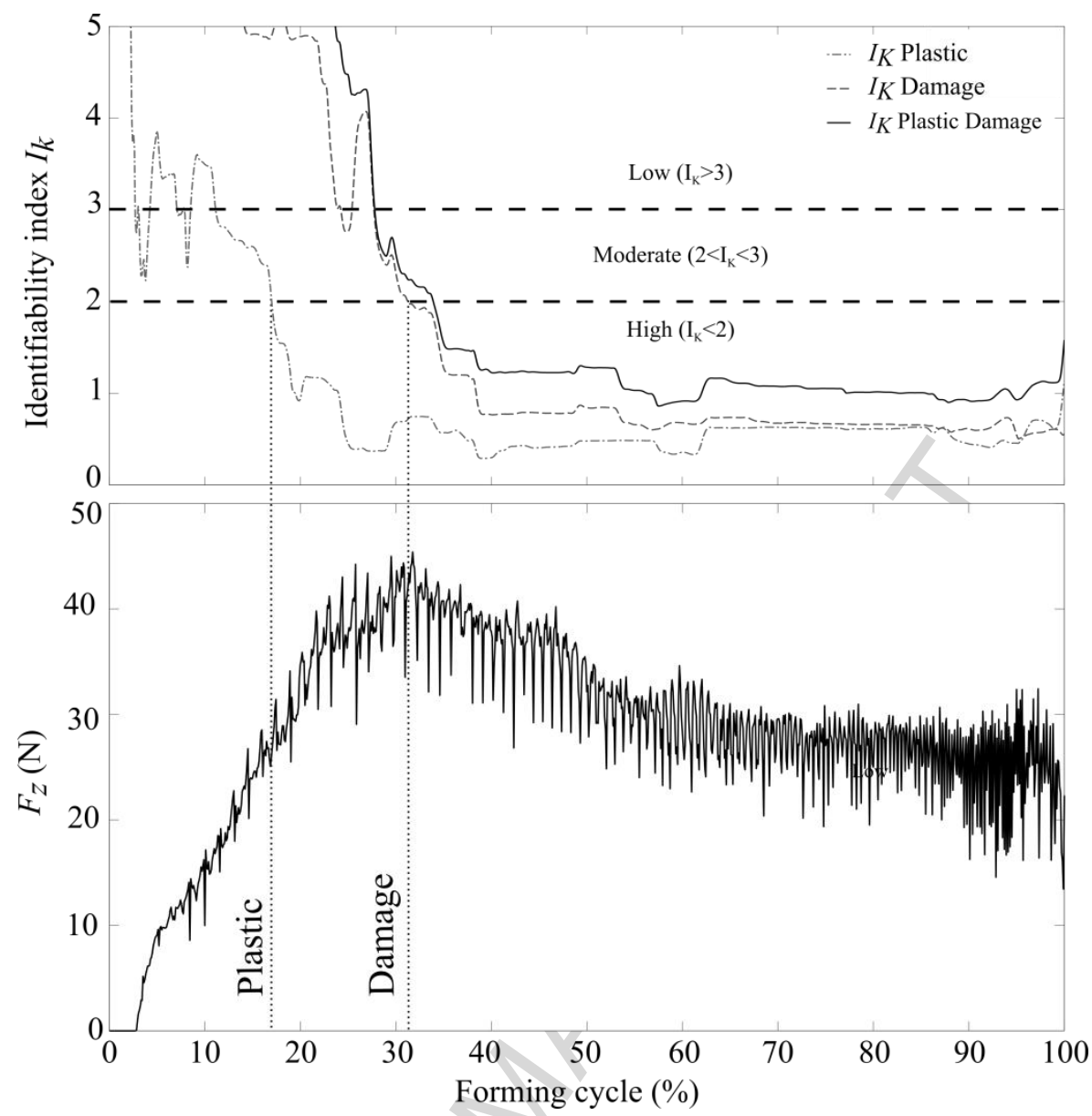

Fig. 17: Evolution of the richness of the forming force for different phenomena to be identified. 


\section{CONCLUSIONS}

This work is dedicated to the complete definition of the identification and identifiability of the ductile damage behavior of ultra-thin sheet metal under notably large strain via the Micro InDef test.

The procedure required the development of a parameterized finite elements model of an instrumented Micro InDef test and the use of software that allows calibration of model from the updating method. The estimation of the plastic and damage parameters consisted of two steps:

1. Tensile tests for the identification of the initial plastic behavior law in the moderate plastic strain $(<30 \%)$.

2. Micro InDef test of a pyramidal shape with the helical forming strategy to calibrate the plastic-damage behavior under very large strain $(>200 \%)$. The minimization function linked to the gap between the numerical and experimental results is based on the axial forming force.

By calculating identifiability index based on the conditioning of the inverse problem, the temporal evolution of the identifiability index during forming for different phenomenon (elastoplastic, damage) measures the richness of the forming force for the phenomena to be identified.

The identifiability analysis, based on the axial forming force sensitivity, was conducted to estimate the reliability of the estimated material parameters. This method leads to a quantification of the performance of the mechanical characterization test for the coupled plastic and damage phases.

The ductile damage model and its associated material parameters were validated by comparing the simulations of different incremental forming processes to experiments.

The following conclusions can be drawn from the present work:

- The initial plastic material parameters obtained from the tensile tests are close to the final calibration. It is impossible to identify the damage law from only tensile test results because the failure is due to both mechanisms: damage growth and necking.

- The results of the validation tests, using the parameters estimated via FEMU method, showed good agreement compared with the experimental measurements.

- The identifiability analysis demonstrates the advantage of using instrumented deformation process for determining the meaningful mechanical properties of thin sheets under very large strain (in regards to the material in this study, approximately $240 \%$ ). 
- The evolution of the identifiability index during forming cycle allows us to determine the richness of information of the experimental axial forming force for the phenomena to be studied.

Future studies will focus on the application of the proposed test as a characterization method with more complex models. Typically the effect of anisotropy, kinematic hardening or multiple hardening and more complex damage laws will be considered.

We can also mention that a fully parametric definition of deformations paths will be defined by coupling identifiability method and toolpath generation with NURBS curves. This allows us to define the best path to identify more complex behavior laws.

\section{Acknowledgments}

This work is under the framework of MicroConnect Project funded by the $17^{\text {th }}$ FUI Call from Banque Publique d'Investissements (FUI Projects - BPI France). The authors of this work gratefully acknowledge the support provided by the MIFHySTO platform, as well as Dr. Gérard Michel and Mr. Martial Personeni for their technical assistance. 


\section{References}

1. Lemaitre J, Chaboche JL (1990) Mechanics of Solid Materials. Cambridge University Press, 544p.

2. Abbassi F, Belhadj T, Mistou S, Zghal A (2013) Parameter identification of a mechanical ductile damage using Artificial Neural Networks in sheet metal forming. Mater Des. 605-615.

3. Shim MS, Park JJ (2001) The formability of aluminum sheet in incremental forming. J Mater. Process Technol. 113: 654-8.

4. Park JJ, Km YH (2003) Fundamental studies on the incremental sheet metal forming technique. J Mater Process Technol. 140, (1-3): 447-453.

5. Jeswiet J, Micari F, Hirt G, Bramley A, Duflou J, Allwood J (2005) Asymmetric Single Point Incremental Forming of Sheet Metal. Cirp Ann-Manuf Techn 54: 88-114.

6. Emmens WC, van den Boogaard AH (2009) An overview of stabilizing deformation mechanisms in incremental sheet forming. J Mater Process Technol 209: 3688-3695.

7. Jackson K, Allwood J (2009) The mechanics of incremental sheet forming. J Mater Process Technol 209: 1158-1174.

8. Vollertsen F, Biermann D, Hansen HN, Jawahir IS, Kuzman, K (2009) Size effects in manufacturing of metallic components. Cirp Ann-Manuf Techn 58: 566-587.

9. Ben Hmida R, Thibaud S, Gilbin A, Richard F (2013) Influence of the initial grain size in single point incremental forming process for thin sheets metal and microparts: Experimental investigations. Mater Des 45: 155-165.

10. Hall EO (1951) The Deformation and Ageing of Mild Steel: III Discussion of Results. Proc Phys Soc Sect B 64, 747.

11. Petch NJ (1953) The cleavage strength of polycrystals. J Iron Steel Inst Lond. 173: 25-28.

12. Henrard C, Bouffioux C, Eyckens P, Sol H, Duflou J, Van Houtte P, Van Bael A, Duchêne L, Habraken AM (2011) Forming forces in single point incremental forming: prediction by finite element simulations, validation and sensitivity. Comp Mech 47: 573-590.

13. Duflou J, Tunçkol Y, Szekeres A, Vanherck P (2007) Experimental study on force measurements for single point incremental forming. J Mater Process Technol 189: 65-72.

14. Kavanagh KT, Clough RW (1971) Finite element applications in the characterization of elastic solids. Int J Sol Struct, 7 (1): 11-23 
15. Pottier T, Toussaint F, Vacher P (2011) Contribution of heterogeneous strain field measurements and boundary conditions modelling in inverse identification of material parameters. Eur J Mech A/Solids. 30 (3): $373-382$

16. Gelin JC, Ghouati O (1994) An inverse method for determining viscoplastic properties of aluminium alloys. J Mater Process Technol. 45: 435-440.

17. Ghouati O, Gelin JC (1998) Identification of material parameters directly from metal forming processes. J Mater Process Technol. 80-81: 560-564.

18. Yoshida F, Urabe M, Toropov V (1998) Identification of material parameters in constitutive model for sheet metals from cyclic bending tests. Int J Mech Sci. 40: 237-249.

19. Gréban F, Monteil G, Roizard X (2007) Influence of the structure of blanked materials upon the blanking quality of copper alloys. J Mater Process Technol. 186: 27-32.

20. Lemaitre J, Desmorat R (2005) Engineering damage mechanics. Springer, Berlin, 380p.

21. Kachanov L (1958) Time of the Rupture Process under Creep Conditions. Izv Akad Nauk SSR Otd Tech Nauk. 8: 26-31.

22. Rabotnov YN (1969) Creep Problems in Structural Members. Amsterdam: North- Holland; 822 pp.

23. Voce E (1955) A practical strain hardening function. Metallurgia. 51(307): 219-226.

24. Bouchard PO, Bourgeon L, Fayolle S, Mocellin K (2011) An enhanced Lemaitre model formulation for materials processing damage computation. Int J Mater Form. 4 (3): 299-315.

25. Levenberg K (1944) A method for the solution of certain non linear problems in least squares. Quart Appl Math. 2: 164-168.

26. Marquardt D (1963) An algorithm for least squares estimation of non linear parameters. J Appl Math. 11 : $431-441$.

27. Richard F (1999) MIC2M: Modélisation et Identification du Comportement Mécanique des Matériaux. http://mic2m.univ-fcomte.fr

28. Ambrogio G, Filice L, Micari F (2006) A force measuring based strategy for failure prevention in incremental forming. J Mater Process Technol. 177: 413-416.

29. Thibaud S, Ben Hmida R, Richard F, Malécot P (2012) A fully parametric toolbox for the simulation of single point incremental forming process: Numerical feasibility and experimental validation. Sim Mod Pract Theo. 29: 32-43. 
30. Moës N, Dolbow J, Belytschko T (1999) A finite element method for crack growth without remeshing. Int J Num Meth Eng. 190: 6825-6846.

31. Hallquist J (2006) LS-DYNA® Theory Manual.

32. Bouffioux C, Lequesne C, Vanhove H, Duflou JR, Pouteau P, Duchêne L, Habraken AM (2011) Experimental and numerical study of an AlMgSc sheet formed by an incremental process. J Mater Process Technol. 211: 1684-1693.

33. Guzmán CF, Yuan S, Duchêne L, Flores EIS, Habraken AM (2017) Damage Prediction in Single Point Incremental Forming using an Extended Gurson Model, International Journal of Solids and Structures.

34. Brun R, Reichert P, Künsch H (2001) Practical identifiability analysis of large environmental simulation models. Water Resources Research. 37: 1015-1030.

35. Gujarati D (2004) Basic Econometrics. fourth ed, McGraw-Hill, Irwin.

36. Richard F, Villars M, Thibaud S (2013) Viscoelastic modeling and quantitative experimental characterization of normal and osteoarthritic human articular cartilage using indentation. J Mech Beh Biomed Mater. 24: 41-52. 

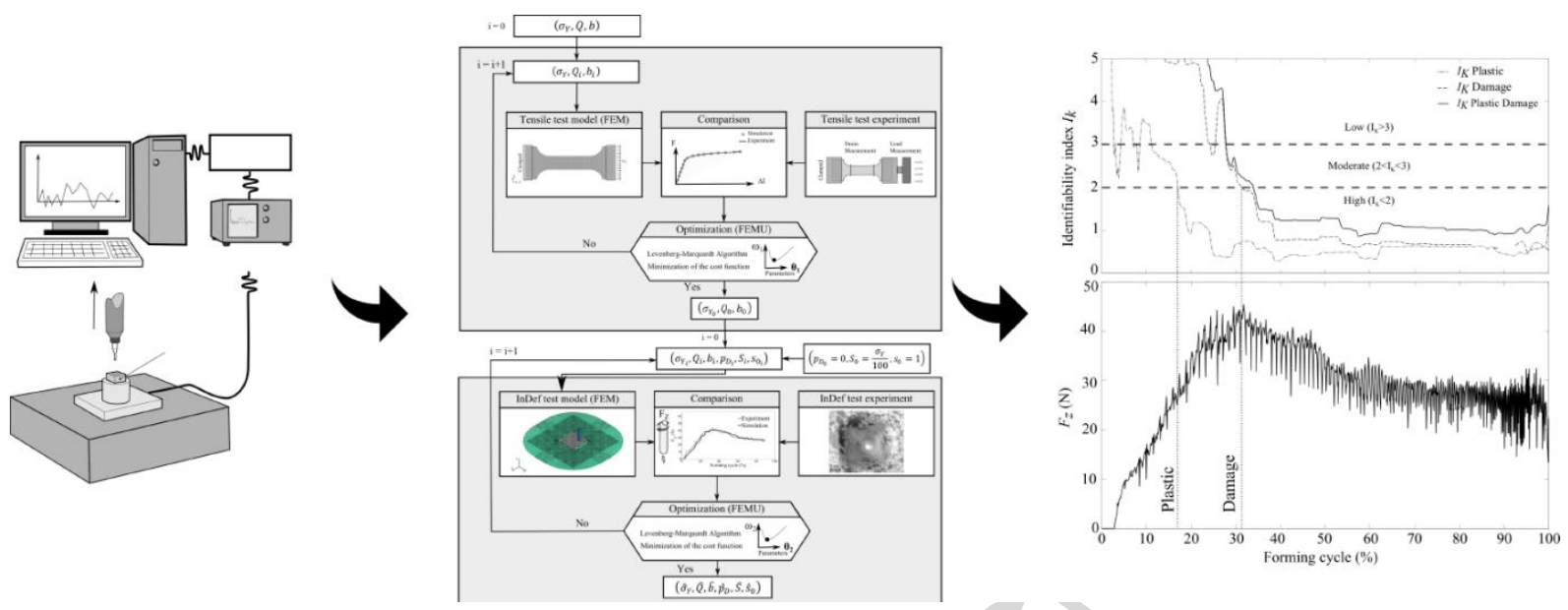

Graphical abstract 


\section{Highlights}

- Estimation of material parameters from micro incremental sheet forming test using forming force measurements by finite element model updating method.

- Identification of coupled ductile damage behavior in very large strain of thin copper foils during incremental deformation test.

- Quantification of forming force information richness with an identifiability index to ensure no correlation between the material parameters and to enable an optimization of the characterization test. 